Canadian

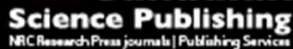

Canadian Geotechnical Journal Revue canadienne de géotechnique

\title{
Geosynthetic reinforced column supported embankments and the role of ground improvement installation effects
}

\begin{tabular}{|c|c|}
\hline Journal: & Canadian Geotechnical Journal \\
\hline Manuscript ID & cgj-2017-0036.R2 \\
\hline Manuscript Type: & Article \\
\hline Date Submitted by the Author: & 13-Aug-2017 \\
\hline Complete List of Authors: & $\begin{array}{l}\text { King, Daniel; Golder Associates Pty. Ltd. } \\
\text { Bouazza, Abdelmalek; Monash University } \\
\text { Gniel, Joel; Golder Associates Pty Ltd } \\
\text { Rowe, Kerry; Queen's University, Civil Engineering } \\
\text { Bui, Ha; Monash University, Civil Engineering }\end{array}$ \\
\hline $\begin{array}{r}\text { Is the invited manuscript for } \\
\text { consideration in a Special } \\
\text { Issue? : }\end{array}$ & $\mathrm{N} / \mathrm{A}$ \\
\hline Keyword: & $\begin{array}{l}\text { Field case study, geosynthetic, column supported embankment, installation } \\
\text { effects }\end{array}$ \\
\hline
\end{tabular}




\section{Geosynthetic reinforced column supported embankments and the role of}

\section{ground improvement installation effects}

Daniel J. King ${ }^{1}$

Abdelmalek Bouazza ${ }^{2 *}$

Joel R. Gniel ${ }^{3}$

R. Kerry Rowe ${ }^{4}$

Ha H. Bui ${ }^{5}$

*Corresponding author

${ }^{1}$ Geotechnical Engineer, Golder Associates Pty. Ltd. Building 7, Botanicca Corporate Park, 570 - 588 Swan Street, Richmond, Victoria, 3121, Australia. Email: dking@golder.com.au (formerly Monash University)

${ }^{2}$ Professor, Department of Civil Engineering, 23 College Walk, Monash University, Melbourne, Victoria, 3800, Australia. Email: malek.bouazza@monash.edu

${ }^{3}$ Associate, Principal Geotechnical Engineer, Golder Associates Pty. Ltd. Building 7, Botanicca Corporate Park, 570 - 588 Swan Street, Richmond, Victoria, 3121, Australia. Email: jgniel@golder.com.au

${ }^{4}$ Professor and Canada Research Chair in Geotechnical and Geoenvironmental Engineering, GeoEngineering Centre at Queen's-RMC, Queen's University, Ellis Hall, Kingston, ON, Canada K7L 3N6. Email: kerry.rowe@queensu.ca

${ }^{5}$ Senior Lecturer, Department of Civil Engineering, 23 College Walk, Monash University, Melbourne, Victoria, 3800, Australia. Email: ha.bui@monash.edu 


\begin{abstract}
For geosynthetic reinforced column supported embankments (GRCSE) supporting a high embankment, lateral forces associated with lateral sliding and embankment stability often govern the acceptability of a given design under serviceability conditions. Frequently, the complex soil-structuregeosynthetic interaction, the size and the three dimensional nature of a GRCSE necessitate the use of numerical analysis to assess embankment performance relative to serviceability criteria. However, traditional finite element method techniques used to model serviceability behaviour are limited in their ability to model the geotechnical mechanisms associated with column installation, equilibration and group installation effects. These installation effects are examined herein based on a GRCSE field case study located in Melbourne, Australia that has been extensively instrumented. The role that these installation effects have on the performance of the GRCSE is highlighted and the behaviour of the columns supporting the embankment is emphasized. It is shown that cracking of the unreinforced columns supporting the embankment is likely inevitable and that the reduction of lateral resistance provided by the columns should be accounted for in design. The suitability of various numerical approaches currently used in design to model the columns supporting the GRCSE, and the embankment itself, are discussed and recommendations made.
\end{abstract}

\title{
Keywords:
}

Geosynthetic, field case study, , column-supported embankment, installation effects 


\section{Introduction}

The design of a geosynthetic reinforced column supported embankments (GRCSEs) requires the consideration of a number of limit state conditions. These typically include, but are not limited to the following: embankment stability, lateral sliding, column group capacity and extent, vertical load distribution (soil arching), reinforcement strain and foundation settlement (Rogbeck et al. 2004; BSI 2010; Lawson 2013). The focus of this paper is on the global scale mechanisms that lead to horizontal deformation, such as lateral sliding, embankment stability and edge instability (column group extent) based on a field case study located in Melbourne, Australia. These mechanisms are particularly important in high embankments, such as the field case study considered herein, where lateral forces are larger.

Assessment of the global scale mechanisms in a GRCSE is dependent on the type of ground improvement (or semi-rigid inclusions) adopted, and for a GRCSE there are a number of options available. Some examples from field case studies include; drilled displacement columns (DDCs) (Briançon et al. 2008; Briançon and Simon 2011; Fok et al. 2012; Wong and Muttuvel 2012), high speed piles (van Duijnen et al. 2010), timber piles (Hsi 2001; van Eekelen et al. 2010) and rammed aggregate piers (Abdullah and Edil 2007). All of these options require the installation of semi-rigid (columns) or rigid (piles) inclusions that cause full-displacement installation effects.

Despite the increasing use of DDCs to support geosynthetic reinforcement embankments the role of installation effects on the behaviour of GRCSEs, and on the installed columns themselves, has not received significant attention. The design methods that do exist for DDCs are largely concerned with the determination of bearing behaviour from empirical methods, which have mostly been developed from in-situ load test results. These approaches relate unit base and shaft resistance to cone penetration test (CPT) tip resistance $\left(q_{\mathrm{c}}\right)$ or standard penetration test (SPT) blow count $(N)$ (Bustamante and Gianeselli 1993, 1998; NeSmith 2002 and Brettman and NeSmith 2005; for example). While these methods may provide a means to calculate bearing capacity, they provide limited insight into installation effects. 
A review of numerous studies that have investigated the global scale behaviour of GRCSEs (Masse et al. 2004; Liu et al. 2007; Jenck et al. 2009; Chatte and Lauzon 2011, Ariyarathne et al. 2012; Zhang et al. 2013; Bhasi and Rajagopal 2015) indicates that numerical analysis techniques are by far the preferred method of analysis for assessing serviceability behaviour. The study of global scale GRCSE mechanisms through full-scale case studies, laboratory scale physical modelling and centrifuge modelling is far less common. However, current finite element method (FEM) numerical techniques are limited in their ability to model large strain problems such as pile installation (Więckowski 2004) and generally advanced methods such as Coupled Eulerian-Lagrangian (CEL) (Qiu et al. 2011; Pucker and Grabe 2012) or point based (meshless) methods such as smooth particle hydrodynamics (SPH) (Bui et al. 2008) or the material point method (MPM) are required. In some cases, "work-around" methods are adopted within a FEM analysis to account for installation effects. Wong and Muttuvel (2012) and Gniel and Haberfield (2015) consider the columns supporting a GRCSE as "geotechnical" elements, which are assumed to be cracked and are modelled as plate elements with little to no bending stiffness. However, in many cases, installation effects are ignored entirely, or not acknowledged, and no position is taken as to the effect that this assumption has on the numerical output.

Whilst this short-coming may sound like a trivial matter, it is well known from field scale observations of pile installation effects, particular for driven piles (Randolph et al. 1979; Coop and Wroth 1989; Lehane and Jardine 1994; Eigenbrod and Issigonis 1996), and through the use of analytical methods such as cylindrical cavity expansion techniques (Carter et al. 1979; Randolph and Wroth 1979; Randolph 2003) and the strain path method (Baligh 1985; Sagaseta and Whittle 2001) that the installation of full displacement piles can induce lateral displacement and excess pore water pressure (pwp) in the vicinity of the pile shaft. This has also been shown recently for an isolated fullscale controlled modulus column (Suleiman et al. 2015) and for a large diameter cast in-situ concrete pipe pile (Liu et al. 2009) that were both extensively instrumented. A limited number of studies have described group installation effects; Poulos (1994) investigated the effects of driving a pile adjacent to a pile in clay, O’Neill et al. (1982) investigated installation effects for a group of steel tube piles and Kitazume and Maruyama (2007) assessed the stability of a group of deep soil mixed columns. The 
cumulative column installation effects, which are relevant for GRCSEs due to the large number of columns/piles installed in a dense array, are considerable more difficult to assess. However, it is thought that a reasonable approximation and insight into group installation effects can be gained by considering the installation of multiple columns within the framework of cavity expansion theory; this is done to assist with and aid the interpretation of the field data.

One of the benefits frequently cited to justify the construction of a GRCSE is the rapid speed of construction permitted compared with unsupported geosynthetic reinforcement embankments, where it is often necessary to monitor the excess pwp responses as the embankment is raised, to ensure that an adequate factor of safety for embankment stability is maintained. As embankment load in a GRCSE is (predominately) transferred directly to the founding unit through load distribution in the load transfer platform (LTP), the behaviour of the soft soil is generally considered to be of little importance when considering embankment behaviour. However, it is shown here, that the excess pwp that develops due to ground improvement works is considerable. Furthermore, where embankment construction proceeds rapidly, and immediately after ground improvement works, this excess pwp in the soft soil underlying the embankment can be expected to reduce the factor of safety against slope stability, increase embankment deformation through enhanced lateral sliding, due to the reduction in effective stresses along the sliding plane, and in addition, impart considerably larger structural actions (bending moments and shear force) on the columns supporting the embankment.

The objective of this paper is to demonstrate the manner in which group installation effects affect the global behaviour of a GRCSE and the columns which support the embankment. In addition, the appropriateness of a number of numerical modelling techniques used to simulate the performance of a GRCSEs are discussed, based on the field case study data presented, and an interpretation of installation effects.

\section{Ground improvement using drilled displacement columns}

In recent years, DDCs have seen increased use largely due to the increased torque capacities of modern piling equipment with penetration depths of up to $30 \mathrm{~m}$ now achievable with drilling tool diameters typically between $200 \mathrm{~mm}$ and $550 \mathrm{~mm}$ (Larisch et al. 2013). This form of ground 
improvement goes by a number of names, auger pressure-grouted displacement piles is the term frequently used in the North American context, while drilled displacement piles or the proprietary named Controlled Modulus Column is frequently used in the European context. Prezzi and Basu (2005) provide an overview of the European and North-American nomenclature. Throughout this paper, the more generic term drilled displacement columns (DDCs) is used for the ground improvement works associated with this case study to distinguish this technique from piling applications.

The construction of a DDC is similar in many respects to the non-displacement continuous flight auger (CFA) pile and has largely evolved from this piling technique. The main difference is the DDC drilling tool that fully displaces the soil during the installation phase. NeSmith (2002) provides a detailed description of the DDC construction process. Similar to a CFA pile, installation data recorded during installation generally comprises time, depth, mast inclination, torque, drilling stem rotation rate and penetration rate. During the concreting phase, additional data is recorded and includes; concrete slurry pressure and lifting speed, which is often used to infer an "as-built" DDC, profile. The use of data acquisition hardware for the monitoring and verification of the DDC installation is an integral part of the ground improvement works that enables the delineation of the sub-surface materials and increased confidence that founding conditions and column integrity are achieved. These construction related aspects form an important part of the GRCSE design, the interested reader is referred to Piscsalko and Likins (2004) and NeSmith and NeSmith (2006) for a more expansive discussion.

\section{Installation effects - general behaviour}

The installation effects associated with a driven pile are well described by Randolph (2003) and summarized briefly here. The three fundamental mechanisms described below, in a generalized form, are applicable to full displacement columnar elements used to support a GRCSE. The installation of a full displacement pile results in severe distortion of the soil in the immediate vicinity of the pile. In the case of a DDC, this distortion includes the effects of auger mechanics as soil is rotated and transported up the auger flights, densified and displaced laterally. In the vicinity of the pile tip the strain fields resembles spherical cavity expansion while further up the pile shaft the strain field 
merges to resemble cylindrical cavity expansion where the soil outside the immediate distorted zone is displaced radially outwards. At the completion of pile installation, an excess pwp field exists around the installed shaft due to: 1) an increase in total stresses as the soil is displaced outwards to accommodate the pile volume and, to a lesser extent, 2) a change in the mean effective stress due to shearing of the soil. After the installation of a driven pile, the equilibration phase commences immediately as excess pwp dissipates radially. The soil in the vicinity of the pile undergoes (inward) radial consolidation, and as a result, increases in strength. In the third phase, pile loading is resisted by shaft friction and base pressure.

\section{Cylindrical cavity expansion theory}

Given the difficulties in modelling the DDC installation effects numerically, cylindrical cavity expansion theory is adopted here to provide a framework to quantitatively compare the cumulative installation effects with the measured field behaviour. Cylindrical cavity expansion theory broadly falls within the "effective stress concepts" for pile design and is typically employed to assess pile bearing capacity (Randolph 2003; Yu 2013). However, it is adopted here to assess the inadvertent effects that column installation has on the surrounding ground, adjacent columns and the embankment itself. Whilst not all of the installation effects are detrimental to embankment performance, the excess pwp and displacement field, which develop due to installation effects often are; particularly where a large number of columns are installed, in a dense array, as is typical for ground improvement works associated with a GRCSE. The zones along a pile shaft where cylindrical cavity expansion theory is broadly applicable (Yu 2013) where described above and are indicated in Fig. 1. These zones broadly resemble the sub-surface conditions encountered in the Melbourne site (described in further detail below, see also King et al., 2016, 2017a, King, 2017): Zone A - Fill, Zone B - Coode Island Silt and Zone C - Fishermens Bend Silt. The cylindrical cavity expansion solutions developed by Randolph and Wroth (1979) describe the excess pore water pressure and displacement field for the soil mass surrounding a driven pile are derived in the Supplementary Materials Section ${ }^{1}$.

\footnotetext{
${ }^{1}$ Supplementary data are available with the article through the journal Web site at (eventual link) 
Examples of excess pore water pressure (pwp) solutions at various times are shown in Fig. 2, these solutions are used to assess the piezometer data presented later in this paper. The soft soil underlying the GRCSE is the Coode Island Silt; the material properties indicated in Fig. 2 are from King et al. (2016). The solutions presented indicate an excess pwp of $121 \mathrm{kPa}$ at the column/soil interface which reduces to $0 \mathrm{kPa}$ at radius $R$, where $R$ is equal to $2.54 \mathrm{~m}$. As excess pwp dissipates radially outward with time $(t)$, excess pwp $(u)$ is reduced at the column/soil interface and increases at values of radius $r>R$, although this increase is minor.

In order to describe the displacement field the following expression for initial radial soil displacement $(\Delta r)$ was proposed by Carter et al. (1980):

[1] $\quad \Delta r=\sqrt{r^{2}+\beta r_{0}^{2}}-r$

where $\beta$ is the displacement ratio, which is the ratio of net to gross cross sectional area of a pile being driven. For a solid (driven) pile $\beta=1$, however, for open ended steel tube piles the value of $\beta$ is less than 1 and depends on the extent to which a soil plug develops in the base of the pile during installation. The DDC should theoretically have a value of $\beta$ equal to 1 , similar to a driven pile. However, it will be shown that the displacement fields that develop due to DDC installation are overpredicted when $\beta=1$ is used. The radial displacement field from Eqn. [1] is shown in Fig. 2 along with the long-term radial consolidation $(t \rightarrow \infty)$ solution. The time-dependent radial displacement during the equilibration phase is the sum of the initial radial displacement and time-dependent radial consolidation. The closed form analytical solution for cylindrical cavity expansion in a (drained) cohesive-frictional material by $\mathrm{Yu}$ and Carter (2002) is also shown for comparison, this solution approximates the long-term case where radial consolidation is complete (i.e., end of equilibration phase).

Cylindrical cavity expansion theory was developed further by Randolph et al. (1979) to described the stress distribution for an expanding cylinder in a work-hardening elasto-plastic soil model (modified Cam-Clay). When an isolated full-displacement pile is driven into a low OCR soil, the initial vertical and horizontal effective stresses ( $\sigma_{\mathrm{v}}^{\prime}$ and $\sigma_{\mathrm{h}}^{\prime}$ respectively) are modified considerably within radius $\mathrm{R}$, with the radial effective stress $\left(\sigma_{\mathrm{r}}^{\prime}\right)$ becoming the major principal stress and both the 
vertical $\left(\sigma_{\mathrm{z}}^{\prime}\right)$ (intermediate principal stress) and circumferential effective stresses $\left(\sigma_{\theta}^{\prime}\right)$ (minor principal effective stress) reduced considerably. For the North Dynon case study (described below) the centerto-center spacing is equal to or less than the radius $\mathrm{R}$. As a result, the stress distributions arising due to the installation of DDCs are expected to overlap for the numerous closely spaced DDCs installed as part of the ground improvement considered herein.

\section{Field case study}

The North Dynon embankment examined herein was one of four GRCSEs constructed as part of the Regional Rail Link project in Melbourne, Australia in 2012. The North Dynon embankment is a $60 \mathrm{~m}$ long widened GRCSE; a farther $120 \mathrm{~m}$ of the widened embankment has more favourable subsurface conditions and did not require ground improvement. The embankment is founded on a $2 \mathrm{~m}$ thick fill unit overlying a sequence of Quaternary aged sediments (Yarra Delta sediments) overlying the Silurian aged Siltstone/Sandstone of the Melbourne formation (Neilson 1992). The near-surface Coode Island Silt, is of particular importance owing to its wide spatial distribution, low undrained shear strength ( $s_{\mathrm{u}}$ typically increases from about $15 \mathrm{kPa}$ to $40 \mathrm{kPa}$ at depth) and its considerable thickness of up to $25 \mathrm{~m}$ in parts. The geological profile is complex and highly variable, with the Coode Island Silt varying from $7 \mathrm{~m}$ to $15 \mathrm{~m}$ along the length of the embankment, the underlying stiff to very stiff clays of the Fishermens Bend Silt unit form the founding unit for the columns. A detailed description of the sub-surface conditions is presented in King et al. (2016, 2017a). The North Dynon embankment is a widened embankment and comprises a lower and upper level LTP with a gabion wall around the periphery of the embankment. Ground improvement works comprised the installation of $450 \mathrm{~mm}$ diameter DDCs installed in multiple stages (Fig. 3) with $1 \mathrm{~m}$ square cast in-place column heads. The lower level LTP was completed after Stage 1 and 2 ground improvement works (146 DDCs installed) while the upper level was completed following Stage $3 \mathrm{a}$ and $3 \mathrm{~b}$ ground improvement works (104 DDCs installed). The instrumentation was installed in two areas (area No. 1 and area No. 2) (Fig. 3), a cross section at the location of area No. 2 is shown in Fig. 4. This paper presents postconstruction survey data as well as inclinometer, piezometer and tiltmeter data. Additional earth pressure cell (EPC) and strain gauge data has been presented in a complimentary paper where the 
localized LTP behaviour was examined (King et al. 2017a). A similar embankment cross section through area No. 1 is presented in King et al. (2017a) along with a more detailed description of the GRCSE design. One of the other four GRCSEs (a back-to-back tied wall embankment) constructed as part of the Regional Rail Link has also been described separately by Gniel and Haberfield (2015).

\section{Piezometer}

A Geotechnical Systems Australia (GSA) vibrating wire piezometer (model 1200) was installed within the Coode Island Silt beneath area No. 1 to a Reduced Level (R.L.) (relative to mean sea level in Australia) of $-3.45 \mathrm{~m}$. The piezometer was installed using a "push-in" place method immediately prior to the commencement of the lower level Stage 2 works. The piezometer was housed in a GSA push-in cone and progressively advanced through the sub-surface materials using a 1-inch steel pipe and a casing, which slides over the push-in housing. The long-term hydrostatic pwp is $39 \mathrm{kPa}$ and indicates a groundwater level of about $0.6 \mathrm{~m} \mathrm{R.L.} \mathrm{although} \mathrm{this} \mathrm{shows} \mathrm{some} \mathrm{seasonal} \mathrm{variation.} \mathrm{It} \mathrm{was}$ proposed to install additional piezometers in both instrumentation areas, however, this could not be done due to installation difficulties (drilling difficulties and obstructions in the fill unit) and constraints related to the construction timeline.

\section{Vertical inclinometers}

Vertical inclinometers No. 1 and No. 2 were installed using a specialist drilling contractor to advance the boreholes using a combination of solid auger and then washbore drilling techniques. The inclinometer casing has a $70 \mathrm{~mm}$ outer diameter and $58.5 \mathrm{~mm}$ inner diameter and was grouted in accordance with the procedure described by Mikkelsen (2002). Inclinometer No. 1 is $22.14 \mathrm{~m}$ in length with the toe of casing at R.L. - 20.19 m (adjacent DDCs were installed to R.L.s between - 14.0 $\mathrm{m}$ and $-16.2 \mathrm{~m})$. The top $250 \mathrm{~mm}$ below the surface of the piling hardstand had a sacrificial protective casing around it. Inclinometer No. 2 casing is $18 \mathrm{~m}$ in length with top of casing at R.L. 2.10 $\mathrm{m}$ and toe at R.L. - $15.9 \mathrm{~m}$ (adjacent DDCs were installed to depth of between R.L. - $12.41 \mathrm{~m}$ and $14.13 \mathrm{~m}$ ). Inclinometer readings were taken at $0.5 \mathrm{~m}$ intervals using the four-pass method recommended by Mikkelsen (2003). The data has been converted to a local longitudinal-transverse co-ordinate systems. 


\section{Tiltmeters}

Three Slope Indicator - MEMS (Micro electro-mechanical systems) bi-axial tiltmeters were cast inplace at various depths within DDC C15 to measure the post-construction tilt of the column. This DDC is in the outer row of columns, beneath the gabion wall in area No. 2. Inclinometer No. 2 is offset $1.6 \mathrm{~m}$ from DDC C15 where the tiltmeters are installed to enable calibration between the two. The MEMS tiltmeters measure $32 \mathrm{~mm}$ in diameter by $190 \mathrm{~mm}$ in length and have an inclination range of $\pm 10^{\circ}$ with resolution of 9 arc seconds which is temperature corrected. The tiltmeters were mounted at various intervals within a $5.91 \mathrm{~m}$ length of $50 \mathrm{~mm}$ diameter PVC pipe installed immediately after the DDC installation similar to the installation of a reinforcement cage. The base of the PVC pipe was left open to avoid the instrumentation becoming buoyant during installation. Tiltmeters No. 1, No. 2 and No. 3 were installed at R.L. - 3.0 m, R.L. - 0.57 m and R.L. $1.71 \mathrm{~m}$ (within the DDC head) respectively.

\section{Field case study - installation effects}

\section{Porewater pressure}

Data from the piezometer in Area No. 1 (Fig. 5) shows the long-term pwp dissipated to a hydrostatic condition over a period of approximately one year. Two major increases in pwp were observed during construction, the first occurred the day after the installation of the columns (day 57) and coincided with the commencement of Stage 2 works and the second coincided with the Stage $3 b$ works. During Stage 2 the pwp increased by approximately $70 \mathrm{kPa}$ and a maximum pwp of $127 \mathrm{kPa}$ was measured. An approximately exponential decay of pwp was observed after installation. The piezometer readings were taken manually during this time making detailed assessment of installation effects difficult. The data recorded during Stage $3 \mathrm{~b}$ works was recorded on 4-hour intervals allowing a more detailed analysis .

The measured increases in pwp are due to: (1) increase in the sub-soil stress due to the embankment load, and (2) increases due to column installation. Regarding point 1, the stress acting in the area between column heads zone was measured by EPC5 (the location of this EPC is shown in the Supplementary Section, Fig S3 ${ }^{1}$ ). By assuming a $1.5 \mathrm{~V}: 1 \mathrm{H}$ stress distribution with depth through the 
fill and Coode Island Silt units the applied vertical stress acting at the level of the piezometer can be estimated. This applied stress acting at RL $-3.45 \mathrm{~m}$ is shown in Fig. 5 and indicates that during Stage 2 works the increase in pwp $(70 \mathrm{kPa})$ is due to column installation alone as the sub-soil stress was 0 $\mathrm{kPa}$ at this time. During Stage $3 \mathrm{~b}$ the increase in pwp was $70 \mathrm{kPa}$ and the calculated increase in applied stress due to embankment loading is just $6 \mathrm{kPa}$. The majority of the measured pwp increase can therefore be attributed to column installation effects and shows a response similar to that observed by O’Neill et al. (1982) for a driven pile group installed into an over-consolidated clay.

A detailed plan view in Fig. 6 indicates the location of the columns installed near area No. 1 during the Stage $3 \mathrm{~b}$ works between days 130 to 134 . The response of the piezometer during Stage $3 \mathrm{~b}$ works is presented in Fig. 7a and the response of the EPCs and strain gauges are shown in Fig. S2 in the Supplementary Section ${ }^{1}$. The instrumentation layout in area No. 1 is shown in King et al. (2017a). A daily increase in pwp can be observed during the working hours ( $7 \mathrm{am}$ to $5 \mathrm{pm}$ ), at the completion of the day's work, partial dissipation of excess pwp occurs overnight. The daily data indicates upper maxima of measured pwp in the range of 125 to $130 \mathrm{kPa}$ and is consistent with the maximum pwp observed on day 57 during Stage 2 works.

To provide a quantitative interpretation of the pwp data, the pwp response due to the installation of ten columns between 11 and 12 September was modelled based on the cylindrical cavity expansion theory outlined above and in further detail in the Supplementary Section ${ }^{1}$. Over an area of $9 \mathrm{~m}$ by $7 \mathrm{~m}$, and based on the Coode Island Silt properties at R.L. $-3.45 \mathrm{~m}$ (depth of piezometer), $s_{\mathrm{u}}=25 \mathrm{kPa}$ and $G=3200 \mathrm{kPa}$ (King et al. 2016), the time-dependent axisymmetric equations for each column installation were solved. Based on these parameters, axisymmetric solutions plotted at various times after installation are presented in Fig. 2, these solutions provide an indication of the magnitude of pwp increase in the vicinity of an isolated column as well as the rates of pwp dissipation. The calculated excess pwp surfaces were super-imposed in a spreadsheet application to assess the cumulative installation effect. Solutions at day 131 midday and 4 pm, day 132 at 8 am and 4 pm and day 133 at 8 am are presented (Fig. 8a, b, c, d and e, respectively) representing the major periods of pwp installation and equilibration. Fig. $8 \mathrm{f}$ compares measured and calculated excess pwp. The excess pwp

\footnotetext{
${ }^{1}$ Supplementary data are available with the article through the journal Web site at (eventual link) 
was calculated as absolute pwp reading less the initial pwp of $59.9 \mathrm{kPa}$ (see Fig. 5). The magnitude of discrepancy in pwp between the calculated solutions and measured pwp is considerable and the zone of influence predicted by cylindrical cavity expansion theory is not consistent with the observed data. The initial pwp distribution (Fig. 2) reduced to $0 \mathrm{kPa}$ at a radius of $2.54 \mathrm{~m}$. This is not consistent with the increase in pwp observed following the installation of columns $\mathrm{J} 2$ and $\mathrm{H} 3$ located at a radial distance of $13.9 \mathrm{~m}$ and $8.1 \mathrm{~m}$ respectively. Similarly, increases in pwp were observed on days 133 and 134 due to columns installed at radial distances greater than $12.4 \mathrm{~m}$ and $11.4 \mathrm{~m}$ respectively. Increases in pwp at a radial distance $>2.54 \mathrm{~m}$ were predicted to occur as part of the equilibration phase (Fig. 2), however these increases were minor and did not increase until a number of day after installation. The cylindrical cavity expansion theory described above was developed for an elastic perfectly-plastic soil model to predict excess pwp; shear induced pwp is not described by this approach. Some portion of the difference in calculated and observed pwp can be attributed to this effect, however, for slightly over-consolidated soil such as the Coode Island Silt this contribution is expected to be relatively small (Randolph 2003). It follows then that the difference arises due to the initial pwp distribution adopted at the time of installation. It is suggested that this difference is due to hydraulic fracturing of the Coode Island Silt in the vicinity of the column shaft. This behaviour has been previously shown for displacement piles by Massarsch and Broms (1977), Randolph et al. (1979) and Asaoka et al. (1994). The hydraulic fracturing of soils due to deep mixed columns by Shen et al. (2003) and Shen et al. (2004) and in grouting applications by Gottardi et al. (2008) and Marchi et al. (2013) is also well documented.

\section{Lateral deformation}

Two inclinometers described the lateral deformation of the embankment. Inclinometer No. 2 was installed beyond the embankment footprint to assess both column installation effects and long-term embankment behaviour. Inclinometer No. 1 was installed within the embankment footprint to assess installation effects and was decommissioned at the completion of Stage 1 works. The data from Inclinometer No. 1 is described by five phases, where a phase is one or more column installations 
followed by a reading. The lateral displacement measured by Inclinometer No. 1 is similar to data from Inclinometer No. 2 and is presented in the Supplementary Section ${ }^{1}$.

The location of Inclinometer No. 2 and its axes, along with adjacent installed columns, is presented in Fig. 9. Information relating to the installed columns and inclinometer readings is presented in Table 1 and includes the radial distance $(r)$ between inclinometer and installed column, $r / D$ ratio ( $D$ is column diameter) and time between installation and a subsequent inclinometer reading. The incremental transverse lateral displacement for the three phases and sub-surface conditions are shown in Fig. 10 along with the predicted lateral displacement based on Equation [1]. The general shape of the lateral displacement profile (due to installation) is consistent among the various phases and is consistent with data from Inclinometer No. 1 (data and analysis presented in Supplementary Section $^{1}$ ). A large outward lateral movement in the transverse direction was measured, particularly near the upper surface of the Coode Island Silt, and the magnitude of lateral movement generally correlates with the radial distance. A maxima of lateral displacement of up to $35 \mathrm{~mm}$ is generally observed at about $2 \mathrm{~m}$ below the fill-Coode Island Silt interface (R.L. $-2 \mathrm{~m}$ ). For Inclinometer No. 1 the maxima is up to $60 \mathrm{~mm}$. It appears that both the overlying stiff fill unit and column socket in the stiff Fishermens Bend Silt act as lateral restraints. However, Larisch et al. (2014) also observed similar behaviour in a soil profile comprising stiff clay overlying hard clay. It is inferred, therefore, that this displacement response is dominated by soil heave during the first few meters of penetration (i.e., resembles spherical cavity expansion) and is not due entirely to subsurface conditions. The observed lateral displacement profile results in three points of inflexion in the profile; this has important implications when assessing the structural response of the column later in this paper. Following the outward transverse movement of soil due to column installation, inward lateral movement is also observed associated with radial equilibration of multiple columns.

Assessment of the transverse lateral displacement alone provides only limited insight into the three dimensional nature of the problem. A vector diagram showing the directional and magnitude of lateral movement at R.L. $-3.55 \mathrm{~m}$ is presented in Fig. 11. Displacement vectors are inversely scaled based on the radial distance (i.e., vector length $\approx 1 / r$ ) and a resultant vector for each phase is shown.

\footnotetext{
${ }^{1}$ Supplementary data are available with the article through the journal Web site at (link) 
The directional component of soil movement was predominately in the transverse direction away from the embankment (-ve Y-axis) with a minor component of movement in the longitudinal direction (+ve $\mathrm{X}$-axis). The resultant phase vectors do not align precisely with the measured soil movement, although the general agreement is good and the difference is attributed to the non-symmetric arrangement of columns over a larger area than that shown in Fig. 9 (see Fig. 3).

\section{Cumulative installation effects}

Multiple columns were installed for Stage 3a and 3b works; these installation effects are assessed through the data from Inclinometer No. 2. The dates of the inclinometer readings and their relationship with the various stages of ground improvement works are shown in Table 2. Various cumulative and incremental inclinometer profiles are plotted in the transverse (Y-axis) direction (Fig. 12) and the locations of the tiltmeters are also indicated (described further below). The longitudinal movement (X-dir.) during this period was minimal. The first three cumulative profiles show the lateral displacement due to Stage 1, Stage $3 \mathrm{a}$ and Stage $3 \mathrm{~b}$ works. The fourth profile shows the longterm behaviour over a period of 660 days (day 160 to 741). The lateral displacement measured during this period corresponds to the period where the Coode Island Silt has undergone long-term equilibration and is observed as $10 \mathrm{~mm}$ of movement towards the embankment. A further five incremental profiles are shown which describe the installation and/or equilibration phases associated with Stage 3a, Stage 3b works and the long-term condition. For these phases, installation causes movement away from the embankment and equilibration cause movement towards the embankment. The response due to the Stage 1 works (Fig. 10) was the same.

The equilibration causes inward movement of the columns that is in a direction opposite to the outward movement of the embankment caused by lateral spreading and/or embankment instability. The equilibration imposes lateral movement and loadings on the columns that are not typically considered, or recognized, when describing GRCSE behaviour based on numerical analysis that ignored installation effects. 


\section{Field case study - global scale mechanisms}

When designing a GRCSE, there are a number of limit states conditions to be considered. For the North Dynon embankment considered here, the ultimate axial capacity of the individual columns, and the column group capacity, was investigated by King (2017) based on dynamic load test results and these results indicate sufficient single, and group, column capacity. Despite this, the observed vertical settlement of the gabion wall was between $10 \mathrm{~mm}$ and $40 \mathrm{~mm}$ post-construction (average $24 \mathrm{~mm}$ ) over a period of about 1-year post-construction. The larger values of settlement correspond with sections of gabion wall that are highest (eastern end in Fig. 3). This post-construction settlement is explained by the post-construction development of arching described in detail by King et al. (2017a). Normalized settlement is plotted relative to arching development, quantified by the stress reduction ratio (sub-soil stress/overburden pressure), in Fig. 13 and the agreement is excellent. At the completion of embankment construction, the stress reduction ratio was about 0.7 and this decreased to a value of 0.1 as maximum arching conditions developed at about day 600 onwards. This is consistent with the column load increasing from $164 \mathrm{kN}$ to $340 \mathrm{kN}$ for the unit cell in area No. 2 described in King et al. (2017a); a 110\% increase. This highlights the effect that the post-construction development of arching can have on the total embankment settlement. This result is not entirely unexpected. The lateral deformation of the embankment also shows similar time-dependent postconstruction behaviour, this is however, more difficult to explain and is examined over the remainder of the paper.

Lateral sliding, overall stability and column group extent limit states (Fig. 14) may cause lateral deformation of a GRCSE. For this case study, the column group extent is satisfied by ensuring the limit states relating to the soil reinforced gabion wall construction (i.e., reinforcement failure/pull-out, analysis of connections and allowable eccentricity) are met (see EBGEO; German Geotechnical Society 2010 , for a full list of limit states relating to soil-reinforced walls). The present study focuses on the assessment of overall stability and lateral sliding mechanisms. 


\section{Long term embankment behaviour}

The long-term lateral movement of the embankment is assessed through tiltmeter and inclinometer data as well as post-construction survey data. The magnitude of lateral displacement (day 182 to 894) is indicated with survey vectors in Fig. 15 and shows between $10 \mathrm{~mm}$ and $25 \mathrm{~mm}$ of movement. The survey markers are located at the mid-height of the gabion wall which varies from between $5 \mathrm{~m}$ and $6.5 \mathrm{~m}$ high (survey markers 1 to 4 ) and between $3 \mathrm{~m}$ and $4 \mathrm{~m}$ (survey markers 5 to 10 ). All of the 10 survey markers show consistent behaviour and indicate that the entire length of the gabion wall, and by inference a portion of the embankment itself, has moved in a southerly direction with larger movement generally occurring near the southeast end where the wall height is greatest. A large component of lateral deformation is in the longitudinal direction and this cannot be explained by (transverse) rotation of the soil-reinforced gabion wall, as is often the case. Furthermore, the lateral movement along the length of the gabion wall is not consistent with embankment behaviour caused by the overall stability or column group extent limit states as no significant wall rotation has been observed and the lateral movement is occurring out-of-plane (i.e. it is not occurring in the direction normal to the gabion wall).

The long-term lateral movement (day 161 to 741 ) at the base of gabion wall, and through subsurface profile, is shown in Fig. 16 based on the data from Inclinometer No. 2 (offset $1.6 \mathrm{~m}$ from the gabion wall). The inclinometer data indicates about $10 \mathrm{~mm}$ of outward transverse movement and 5 $\mathrm{mm}$ of longitudinal movement (at R.L. $2 \mathrm{~m}$ ), a result of $11 \mathrm{~mm}$ in an approximate southerly direction that is consistent with survey data (survey marker 7) at this location. The uniform lateral movement at the base and mid-height of the gabion wall suggest a lateral sliding mechanism, not wall rotation, is primarily responsible for the post-construction movement.

In addition to the outward lateral movement at the base of the LTP (R.L. 2 m) there is also considerable lateral movement within the Coode Island Silt in an inward direction; the opposite to the outward transverse movement observed during DDC installation (see Fig. 10 and Fig. 11) that is due to radial equilibration of the installed columns. The lateral sliding and column equilibration mechanisms occur in approximately equal direction with a neutral axis in the transverse direction at about R.L. $-1 \mathrm{~m}$. 
The long-term tiltmeter measurements (Fig. 17) show the tilt in the outer row DDC C15, supporting the gabion wall in area No. 2 (see Fig. 9). The transverse axis of the two tiltmeters show long-term outward rotation consistent with the inclinometer profile (Fig. 16). Between day 161 and 741 the rotation of tiltmeter No. 2 and No. 3 in the Y-axis direction was $-0.36^{\circ}$ and $-0.32^{\circ}$ respectively. Assuming the DDC column and head rotate uniformly about a neutral axis at R.L. - $1 \mathrm{~m}$, then the lateral displacement at R.L. $2 \mathrm{~m}$ (base of LTP) is $17 \mathrm{~mm}$ based on the average of the two tiltmeter readings. In the longitudinal direction, the angle of tilt measured by the inclinometer above R.L. $0 \mathrm{~m}$ is just $+0.02^{\circ}$ (72 arcseconds). The rotation of tiltmeter No. 2 and No. 3 in the X-axis is +6 arcseconds and +79 arcseconds at a resolution of \pm 9 arcseconds. On this basis, it is inferred that the column head, LTP and gabion wall are translating laterally with minimal rotation in the longitudinal direction. Due to the complex nature of the long-term displacement profile of the column it is difficult to back-calculate a deflected profile based on discrete rotational measurements (tiltmeter data). Despite this, the agreement among the inclinometer, tiltmeters and survey data is considered good.

In Fig. 18 the long-term lateral movement of the gabion wall is shown along with the excess pwp. Both displacement and pwp were normalized with respect to the maximum lateral displacement and maximum excess pwp respectively. Lateral movement of the embankment stabilized by around day 400 , which was consistent with the general dissipation of the excess pwp. While the radial equilibration of the columns was governed by the dissipation of excess pwp, it is shown here that the lateral sliding mechanism was also influenced by the dissipation of excess pwp. Based on the inclinometer, tiltmeter and survey data, the long-term lateral movement of the GRCSE can be described by:

1) Outward lateral (block) sliding of the embankment due to the out of balance active earth pressure force acting on the gabion wall; the plane of sliding is however not sharply defined but represents a broad shear zone in the fill and upper portion of the Coode Island Silt, and

2) Inward lateral movement in the Coode Island Silt associated with radial equilibration of the numerous installed DDCs.

Both of these mechanisms act in approximately opposite directions, and are related to the dissipation of excess pwp beneath the embankment due to column installation effects. This was measured directly 
through piezometer data, observed indirectly as heave/uplift ${ }^{1}$ and predicted based on cylindrical cavity expansion theory. The large build-up of excess pwp beneath the GRCSE present at the completion of embankment construction is expected to have greatly reduced the effective stresses (in particular vertical effective stress) in the upper portion of the Coode Island Silt, and as a result, reduced the lateral resistance provided by the Coode Island Silt. This is inferred to have aided the lateral sliding mechanism and is consistent with the lateral sliding largely ceasing as excess pwp in the upper portion of the Coode Island Silt dissipated by about day 400. The dissipation of excess pwp in the middle of the CIS is expected to have taken much longer and this is consistent with the tiltmeter data that indicates that the rotation of the columns did not stabilize until about day 700 as the equilibration of the columns continued; about two years after the completion of the ground improvement works.

It follows that the critical period with respect to embankment stability was the end of construction when the embankment was at full height and excess pwp due to ground improvement works had not dissipated greatly. This is particularly the case where a GRCSE has been constructed quickly, which is a benefit frequently cited to justify their use in the first instance. Due to the reduction in effective stress in the upper portion of the Coode Island Silt, the lateral sliding mechanisms must therefore be resisted by the flexural capacity of the DDCs and the passive resistance provided by the fill unit around the periphery of the embankment. The combined effect of outward lateral sliding and inward equilibration subjects the columns to considerably greater internal stresses than would otherwise be expected if installation effects were ignored.

\section{Structural response of drilled displacement columns}

As instruments to measure bending moments directly are not currently available, it is common to calculate the bending moment indirectly from curvature and material properties as follows:

[2] $M=\psi E I$

where $M, \psi, E$ and $I$ are the bending moment, curvature, modulus of elasticity and second moment of inertia of the column respectively. Where the bending moment exceeds $M_{\mathrm{cr}}$, cracking of the column

\footnotetext{
${ }^{1}$ Supplementary data are available with the article through the journal Web site at (link) 
will occur and as a result the cross sectional area is reduced. The effective moment of inertia $I_{\mathrm{e}}$ for a cracked section is calculated as follows (Branson 1977):

[3] $I_{\mathrm{e}}=\left[\frac{M_{\mathrm{cr}}}{M}\right]^{3} I_{\mathrm{g}}+\left[1-\left(\frac{M_{\mathrm{cr}}}{M}\right)^{3}\right] I_{\mathrm{cr}} \leq I_{\mathrm{g}}$

The flexural failure of an unreinforced concrete column is a brittle failure mechanism and the use of Eqn. [2] and Eqn. [3] is not strictly valid, and for this reason, the calculated crack depth should be considered as approximate only and is likely a lower bound. For inclinometer derived lateral displacement profiles, curvature can be calculated using Eqn. [4], however, typically $\mathrm{d} z / \mathrm{d} w$ is assumed to be close to zero and the approximate expression (Eqn. [5]) is adopted. Curvature can be calculated directly from a lateral displacement profile using Eqn. [5], however, whilst the inclinometer profile with depth may appear "smooth" it is comprised of discrete inclination readings with depth. As a result, the direct use of Eqn. [5] generally leads to erratic and unrealistic results. To calculate the bending moment profile more accurately it is necessary to fit a continuous curve to the displacement profile (i.e. curve-fitting techniques are required)(Ooi and Ramsey, 2003).

[4] $\psi=\frac{\frac{\mathrm{d}^{2} w}{\mathrm{~d} z^{2}}}{\left[1+\left(\frac{\mathrm{d} w}{\mathrm{~d} z}\right)^{2}\right]^{3 / 2}}$

[5] $\quad \psi \sim \frac{\mathrm{d}^{2} w}{\mathrm{~d} z^{2}}$

Ooi and Ramsey (2003) compared 12 curve fitting methods applied to 60 sets of inclinometer data and concluded that a piecewise cubic curve fitting over a 5 point window generally resulted in the best estimate of back-calculated bending moment profiles. The piecewise cubic curve fitting approach fits a cubic polynomial $w=A z^{3}+B z^{2}+C z+D$ over a moving window of adjacent data points. In the supplementary section the 5-point data window recommended by Ooi and Ramsey (2003) is shown along with larger data windows (9 no., 11 no., and 13 no.) and higher-order polynomial approximations (Fig. S10 ${ }^{1}$ ) based on the lateral displacement profile in Fig. $16^{1}$. Using the average of multiple piecewise cubic functions at a data point, the curvature can be calculated explicitly from Eqn. [6].

\footnotetext{
${ }^{1}$ Supplementary data are available with the article through the journal Web site at (link) 
[6] $\quad \psi \sim \frac{\mathrm{d}^{2} w}{\mathrm{~d} z^{2}}=6 A z+2 B$

The use of larger data windows results in increased "smoothing" of the data sets. Engineering judgement is required to obtain an appropriate balance between a profile that is "smoothed" and localized behaviour. The higher order polynomials generally provide a good fit of the displacement profile, however, the bending moment profiles show erratic and unpredictable behaviour at the top and bottom and are not utilized here; Ooi and Ramsey (2003) made a similar recommendation. The 11-point data window is adopted herein as the preferred method based on analysis of the postconstruction lateral displacement profile (Fig. 16) presented in the Supplementary Section ${ }^{1}$.

The post-construction survey of the embankment indicated that the outward deformation of the embankment was approximately within the allowable limits which satisfy a zero tensile strain (Fig. $\mathrm{S}^{1}$ ) (i.e., about $20 \mathrm{~mm}$ ), if it is assumed that the columns supporting the GRCSE rotate uniformly outwards due to lateral sliding alone (this is shown in detail in the Supplementary Section ${ }^{1}$ ). A zero tensile strain condition occurs where the tensile stress induced in the column due to flexure is less than, or equal to, the axial (compressive) stress $(N)$ (see Fig. $S 9^{1}$ ). However, the bending moments induced in the DDCs are subjected to the combined effects of lateral sliding and equilibration acting in (approximately) the opposite direction (Fig. 16) and when these actions are considered, not only are tensile stresses induced in the column, but cracking of the column occurs. Due to the rotational restraint provided by the DDC head, and to a lesser extent the fill unit, as well as the rotational restraint at the bottom of the column due to the socket into the Fishermens Bend Silt founding unit, flexural cracking is predicted beneath the column head ( R.L. $-1 \mathrm{~m})$, above the location of maximum lateral deflection $(\sim$ R.L. $-4 \mathrm{~m})$ and above the column socket ( R.L. -9 m). Post-construction survey does little to reveal the additional loadings due to radial equilibration occurring below the ground surface.

The behaviour of DDC C15 has however been subject to additional phases of ground improvement works, which occurred after the column was installed, in addition to the postconstruction lateral sliding and equilibration. In Fig. 19a the behaviour of the DDC C15 during the construction phase is shown (installation to day 161), this includes about $50 \mathrm{~mm}$ of lateral movement due to the Stage $3 \mathrm{a} / 3 \mathrm{~b}$ works. Between R.L. $-6 \mathrm{~m}$ and $-9 \mathrm{~m}, M_{\mathrm{cr}}$ is exceeded. The long-term 
condition (installation to day 741) is shown in Fig. 19b and includes the additional displacement due to lateral sliding and equilibration. The long-term behaviour of the DDC shows flexural cracking at: 1) the upper portion of the shaft (due to the rotational rigidity of the DDC head), and 2) at the mid depth (due to the combined action of lateral sliding and equilibration).

\section{Effects on drilled displacement columns during installation}

Installation effects arising as columns are installed in a dense grid is a problem that affects ground improvement works where semi-rigid inclusions are installed. These effects are not well understood. The installation layout plan adopted for the North Dynon embankment was a square array of columns on a grid size varying from $2 \mathrm{~m}$ to $2.5 \mathrm{~m}$. A hit-1 miss-1 approach was adopted for column installation (Fig. S1 $1^{1}$ ) similar to that described by Plomteux and Porbaha (2004). There are two problems which arise: 1) where adjacent columns are installed in immediate succession and the concrete in the previously installed column has not set, the resulting lateral displacement acts to "squeeze" the previously installed "wet" concrete column, resulting in a loss of cross sectional area (i.e., column “necking”) and 2) where a column is installed adjacent to a partially or fully cured concrete column the previously installed column is subjected to lateral displacement which impose bending moments and shear forces.

\section{Necking of drilled displacement columns}

To assess column necking, the lateral displacement profiles due to the installation of DDC C15 (Inclinometer No. 2 - Phase 3 in Fig. 10 and Table 1) and DDC D10 (Inclinometer No. 1 - Phase 3 in Fig. S5 and Table $\mathrm{S}^{1}$ ) installed at radially offsets of $2.04 \mathrm{~m}$ and $2.41 \mathrm{~m}$ respectively are considered. The measured maximum lateral displacement resulting from the installation of these columns was about $20 \mathrm{~mm}$ and $10 \mathrm{~mm}$ for $\mathrm{C} 15$ and D10 respectively (Fig. 20a). Lateral displacements of between $40 \mathrm{~mm}$ and $60 \mathrm{~mm}$ were measured following the installation of DDCs at offsets of $1.71 \mathrm{~m}$ and $1.12 \mathrm{~m}$ respectively. If displacement profiles of this magnitude are imposed on a DDC, prior to the column setting, lateral translation of the liquid column and simultaneous compression of the cross sectional area, due to the imposed lateral stresses, can be expected. Soil arching will have a beneficial effect, re-

\footnotetext{
${ }^{1}$ Supplementary data are available with the article through the journal Web site at (link) 
distributing lateral stresses around a liquid column, and reducing the lateral displacement in a manner analogous to compression of a tunnel subjected to vertical loading. However, relative displacement between the column interface and the surround soil is required to mobilize soil arching (Iglesia et al. 2013). For a $2 \mathrm{~m}$ square array of columns (2.8 m diagonal spacing), the worst-case scenario is the installation of the four diagonally adjacent columns (each at $2.8 \mathrm{~m}$ ) and an increase in all-round radial stresses on the slurry column. The sum of free-field displacements in each direction (about $5 \mathrm{~mm}$ ) results in a reduction in diameter of $10 \mathrm{~mm}$ that is less than $5 \%$ of the column diameter; this ignores the development of hoop stresses in the soil around the periphery of the column. A hit-1 miss-1 basis is reasonable and this is supported by field observations. However, at closer spacing's, say $1.5 \mathrm{~m}$ center-to-center spacing's (2.1 m diagonal spacing), where free field displacements were measured to be about $20 \mathrm{~mm}$ for an isolated column, it may be necessary to adopt a hit-1 miss-2 approach to increase the spacing between successive column installations to reduce the potential for loss of cross sectional area in the column.

\section{Column installation stresses}

The bending moment profiles calculated from the lateral displacement profiles due to the installation of DDCs C15 and D10 are shown in Fig. 20b and c respectively where these are calculated based on a zero axial stress condition during ground improvement works (column self-weight is ignored). The column is assumed to move laterally with the soil mass; the lateral displacement measured by the inclinometer is therefore considered representative of the column lateral movement. The columns is assessed to crack to a varying extent between about R.L. - $1 \mathrm{~m}$ and $-5 \mathrm{~m}$ however whether this cracking developed in the field is dependent on the extent to which the concrete has hardened and the ductility of the early set concrete. For a column situated within a $2 \mathrm{~m}$ by $2 \mathrm{~m}$ array, bending moments will develop cumulatively due to the installation of adjacent columns. Vector diagrams showing the displacement of an element of soil due to the installation of DDCs was presented in Fig. 11 and Fig. $\mathrm{S} 6^{1}$ for Inclinometer No. 1 and No. 2 respectively, provide an indication of the amount of lateral displacement that the soil mass (and by inference a column) undergoes due to the installation of the

\footnotetext{
${ }^{1}$ Supplementary data are available with the article through the journal Web site at (link) 
surrounding columns. In addition, lateral displacement of over $20 \mathrm{~mm}$ and nearly $10 \mathrm{~mm}$ where measured due to Stage 3a and 3b work (Fig. 12) with a measurable change in column tilt (Fig. 17).

A typical plot of time-dependent concrete strength (Gilbert and Mickleborough 1990) indicates that concrete develops around a third of its strength after three days, and $75 \%$ after seven days. Given the rate of concrete strength development, the time generally taken to complete multiple passes of installation as part of a ground improvement works program and the considerable amount of lateral displacement imposed on a column due to the installation of columns it would seem inevitable, that cracking of unreinforced columns will occur to some extent. The authors consider it is highly unlikely that any practically viable, and theoretically sound, ground improvement approach could be employed to mitigate these detrimental effects associated with column integrity during installation. Whilst the development of flexural cracking is not likely to impact the ability of these columns to carry vertical load in their intended manner, the analysis presented does however raise questions about the ability of the installed DDCs to provide lateral resistance to embankment lateral loading and to resist lateral sliding and global instability.

\section{Discussion}

\section{Implications on the numerical modelling of GRCSEs under serviceability behaviour}

For the North Dynon embankment case study considered here, as with many other GRCSEs, numerical methods are needed to assess the vertical and horizontal deformation of the embankment under serviceability conditions. This is particularly important for high embankments where lateral deformation under serviceability conditions may govern the acceptability of the proposed design. However, the traditional FEM techniques that are often utilized by design engineers are limited in their ability to explicitly model column installation effects and radial equilibration, yet alone group effects and in-turn the affect that these have on the performance of the other columns and embankment itself. These group effects are seldom modelled explicitly as part of routine design, if at all. These mechanisms include:

1) lateral displacement due to the installation of multiple columns in a dense array leading to induced internal forces and bending moments; the potential for column cracking is 
extremely high, if not inevitable, in unreinforced columnar elements

2) the build-up of excess pwp beneath a GRCSE due to ground improvement, a reduction in effective stresses (in particular the vertical effective stress $\sigma_{\mathrm{v}}^{\prime}$ ), and by inference, enhanced lateral sliding due to the reduction in lateral resistance. This will further induce internal forces and bending moments in the columns supporting the embankment; the potential for column cracking is high.

3) radial equilibration of the columns, occurring as a group effect after ground improvement works. This acts in a direction opposite to lateral sliding and greatly increases the internal column forces and bending moments; the potential for column cracking is extremely high These three mechanisms are all related to, and caused by, installation effects. The inability to assess this behaviour in GRCSE is not due to the lack of rigor in the structural assessment but the failure to explicitly model the geotechnical mechanisms involved due largely to the current limitations in the numerical techniques readily adopted in practice. The cavity expansion theories offer an analytical tool, or framework, to describe the governing mechanisms involved, to interpret and evaluate these effects, and by extension, a tool to evaluate group effects. However, the use of cylindrical cavity expansion theory to examine both excess pwp and lateral deformation, as presented here, has limitations. At best, it provides a first-order assessment of the behaviour of installed columns. A solution to the problem of pile/column installation effects, and the group effects affecting a GRCSE is extremely complex. Advances in mesh-less methods (material point method, smooth particle hydrodynamics, discrete element method etc.) as well as other advanced numerical techniques, such as the Coupled Eulerian-Lagrangian (CEL), have enabled researchers to simulate the installation of an isolated DDC (Qiu et al. 2011; Pucker and Grabe 2012; Busch et al. 2013) with mixed success. However, the extension of these methods to model three dimensional group effects on the scale of a typical GRCSE requires considerable computational power and further research to accurately model the coupled hydro-mechanical response of soft soils which is the unit of most interest when assessing the installation effects.

Despite these numerous limitations of traditional FEM techniques (and advanced numerical techniques at this point in time) to model numerically, serviceability behaviour of a GRCSE, solution 
to these problems are required in practice. Recognition of the role that installation effects play in the performance of a GRCSE is an important starting point, and from that, an understanding of the need for "work-around" methods, at this time, to assess serviceability behaviour within a traditional FEM framework. Given the difficulties in explicitly modelling these mechanisms, and the many unknowns that cannot be directly accounted for numerically, a risk-based approach, which reflects this uncertainty it therefore, warranted.

This rationale largely underpins the design approach of modelling DDCs as "geotechnical" elements as described by Gniel and Haberfield (2015) and Wong and Muttuvel (2012). This approach models the columns using plate elements with reduced bending stiffness to simulate the vertical stiffness and the loss of lateral resistance due to column cracking. The lateral spreading of the embankment is assessed by progressively reducing the plate element bending stiffness and assessing the dependency of the embankment deformation to the bending stiffness provided by the columns. The combined effects of lost bending and lateral shear capacity of a cracked column can be simulated, if required, by embedding the plate element in a thin finite element strip with a width of about $2 / 3$ of the column diameter and material properties similar to that of cracked concrete. Typically, values of about $2 \%$ uncracked moment capacity are adopted; a reasonable level of engineering judgement is required to assess the reliance on bending stiffness relative to the potential for column cracking. This is one such approach, that is time consuming, but does provide a more rational approach to dealing with installation effects associated with column integrity and behaviour. However, even with this approach, the build-up in excess pwp and the corresponding reduction in lateral resistance is not explicitly accounted for.

By comparison, numerous studies (Liu et al. 2007; Jenck et al. 2009; Ariyarathne et al. 2012; Zhang et al. 2013; Bhasi and Rajagopal 2015) have modelled the construction and post-construction GRCSE performance with DDCs as "wished into place" structural elements (either a plate element or linear-elastic material), with gross cross sectional properties (i.e., uncracked material properties) and have numerically simulated embankment construction starting with the LTP construction. This approach ignores installation effects, equilibration, the potential for columnar cracking, and as a result, overestimates the lateral resistance provided by the installed columns. It is difficult to conceive a 
scenario where the ground improvement for a typical GRCSE could be undertaken and a dense array of unreinforced columns installed, without inducing considerable shear stresses and bending moments, and to a varying extent, cracking of the columns due to the ground improvement works alone. This does not include the effects of radial equilibration or any form of loading applied by the embankment itself. Serviceability limit state design principles typically adopt partial factors equal to unity for actions, soil parameters and resistances at working loads. However, analysis of field data presented herein suggests that the basis for using gross cross sectional column properties, without strength or stiffness reduction, at working loads (i.e., for serviceability assessment) is poorly supported by experimental observation and has a weak theoretical basis.

An alternative approach suggested by a number of authors (Masse et al. 2004; Chatte and Lauzon 2011) is to design the unreinforced DDCs as "structural" elements satisfying a zero tensile strain condition in order to limit the internal stresses and bending moments. A zero tensile strain condition is invalidated, in nearly all cases, during ground improvement works prior to the embankment construction even beginning, and due to the geotechnical mechanisms that are not explicitly modelled. Despite the findings of the numerical analysis, there can be little confidence that the as-built columns satisfy this zero-tensile strain condition.

\section{A column supported embankment or piled embankment?}

It is the authors experience that referring to these ground improvement elements as "piles" or as a "piled embankment" frequently leads to unnecessary confusion in design scenarios. Furthermore, this belies the design intent of a GRCSE, and that is as a ground improvement option where unreinforced semi-rigid columns are installed and modelled numerically as "geotechnical elements" which reflects the risk of columns cracking. From a design perspective there is (presumably) a higher level of redundancy than a piled structure, and as a result, less onerous pile testing requirements are appropriate. This is the situation for most GRCSEs, as such, the term column, or alternatively, the more general term "semi-rigid inclusion", should be used.

There are of course certain design scenarios, where the geosynthetic reinforced embankment is required to be supported on piles. The piles may comprise driven pre-cast concrete piles, or DDCs with a reinforcement cage installed for example, that have large shear and flexural capacity and 
should be modelled as "structural elements" that satisfy traditional pile design requirements.

Regardless of the piling technique adopted, the nomenclature should reflect the design intent of either a column supported, or pile supported geosynthetic reinforced embankment.

\section{The "ground improvement effect" and the load transfer platform}

The role that sub-soil settlement plays in the development of soil arching and on the performance of the LTP was assessed by King et al. (2017a) for the case study considered here and in King et al (2017b) where serviceability behaviour is considered in greater detail. At this time, there still remains considerable uncertainty in assessing the time rate of sub-soil settlement beneath the LTP due to; 1) uncertainty in the applied load (due to soil arching) acting on the sub-soil and 2) ground improvement affecting sub-soil behaviour. The ground improvement effect includes the radial consolidation of soft soil surrounding individual columns, the build-up of excess pwp and the settlement interaction between columns and the soft soil. However, a great number of researchers have sought to address this first item - soil arching - and considerable progress has been made. At this time, it would seem apparent that the difficulties in describing accurately the ground improvement effects represents a greater barrier to fully understanding LTP behaviour.

\section{Summary of findings}

A number of findings have been outlined based on the assessment of the case study considered herein:

- Total settlement of a GRCSE is affected by the development of maximum arching (see King et al. 2017a) due to the increase in load acting on the column. In the vast majority of embankments, this occurs post-construction.

- For the typical centre-to-centre spacing adopted for a GRCSE, the stress, displacement and pwp fields arising due to installation effects will overlap; installation effects influence the behaviour of a GRCSE as a group effect.

- Excess pwp will develop due to the embankment load distribution in the LTP. However, in most cases, the build-up of excess pwp due to ground improvement works will be considerably greater. 
- The cumulative lateral displacement due to the ground improvement works can be expected to impose considerable lateral, shear and bending stresses on previously installed columns. Due to the slender unreinforced nature of the columns typically adopted for GRCSEs these bending moments will cause cracking of the columns during the installation phase. It is unlikely that a feasible ground improvement program could be implemented to avoid these detrimental effects.

- The dissipation of this excess pwp (equilibration phase) leads to an inward movement of the soil mass beneath the embankment and imposes additional lateral/shear stresses and bending moments on the supporting columns. The assumption that the columns supporting a GRCSE will form an outward cantilever shape during the post-construction phase is an oversimplification of the true behaviour and ignores this equilibration behaviour.

- Numerical analysis used to predict the imposed bending moments in columns supporting a GRCSE cannot be validated by post-construction survey data alone.

- The rapid construction of most GRCSEs limits the time available for the dissipation of excess pwp (due to ground improvement) beneath the embankment. As a result, effective stresses in the soft soil underlying a GRCSE are reduced and, by inference, the lateral resistance available to resist overall stability and lateral sliding mechanisms are reduced. This behaviour is likely to be greater for high embankments.

- The dissipation of excess pwp will lead to strength gain in the soft soil, an increase in effective stress, and will increase lateral resistance available with time, however, this may take a considerable period of time post-construction (dependent on drainage conditions) for the embankment to reach lateral equilibrium. The complete dissipation of the excess pwp through the full thickness of a soft soil will take longer and equilibration may continue for several years post-construction.

- These installation effects may also have a detrimental effect on sensitive infrastructure (shallow foundations, footpaths, underground services etc.) surrounding a GRCSE, however these have not been investigated, the emphasis here has been on the effects to the embankment itself. 


\section{Conclusion}

This paper has investigated installation effects and the role that these have on the performance of a GRCSE. The emphasis is on high embankments, where lateral forces are greater, although many of these findings are not limited to these types of embankments. As a GRCSE increases in height, the performance of the LTP becomes less critical and lateral embankment forces become increasingly critical for overall stability. The data and analysis presented herein have shown that the lateral behaviour of the DDCs for these high GRCSEs, and not their axial capacity, dictates their suitability in the design of a GRCSE for high embankments.

For these embankments numerical modelling is generally required to ensure that acceptable embankment performance can be achieved. Designers using numerical modelling to assess serviceability behaviour of a GRCSE, particularly horizontal deformation, should appreciate the limitations of traditional FEM software to describe the column installation effects, and the associated geotechnical mechanisms, outlined in this paper. A significant quantity of data has been presented highlighting the behaviour of the columns supporting the embankment and questions are raised regarding the integrity of these columns, the likelihood of column cracking and their ability to provide lateral resistance. The numerical modelling of unreinforced concrete columns supporting a GRCSE using gross cross sectional properties, without strength or stiffness reduction, and with no account for the potential for column cracking is highly questionable. Based on the insights from the present study, the design approach described by Gniel and Haberfield (2015) and Wong and Muttuvel (2012), which consider the columns as geotechnical elements, provides an approach that is more robust and theoretically sound than many other design approaches currently in use.

\section{Acknowledgments}

The lead author would like to thank Golder Associates ("Innovation and Excellence" (i2x) award) and Monash University for the financial assistance and support provided to pursue his Ph.D. studies as well as the Regional Rail Link - City to Maribyrnong River (RRLCMR) Alliance for supporting and providing the opportunity to undertake this field case study as well as the use of the post-construction data presented.

https://mc06.manuscriptcentral.com/cgj-pubs 


\section{References}

Abdullah, C. and Edil, T. 2007. Behaviour of geogrid-reinforced load transfer platforms for embankment on rammed aggregate piers. Geosynthetics International, 14(3): 141-153

Ariyarathne, P., Liyanapathirana, D., and Leo, C. 2012. Comparison of different two-dimensional idealizations for a geosynthetic-reinforced pile-supported embankment. International Journal of Geomechanics, 13(6): 754-768

Asaoka, A., Kodaka, T. and Nozu, M. 1994. Undrained shear strength of clay improved with sand compaction piles. Soils and foundations, 34(4): 23-32

Baligh, M. M. 1985. Strain path method. Journal of Geotechnical Engineering, 111(9): 1108-1136

Bhasi, A. and Rajagopal, K. 2015. Numerical study of basal reinforced embankments supported on floating/end bearing piles considering pile-soil interaction. Geotextiles and Geomembranes, 43(6): $524-536$

Branson, D. E. 1977. Deformation of concrete structures. McGraw-Hill Companies, New York.

Brettmann, T. and NeSmith, W. (2005). Advances in auger pressure grouted piles: design, construction and testing. Proceedings of the Advances in Designing and Testing Deep Foundations. Austin, Texas, USA. 24-26 January 2005. ASCE. pp. 262-274.

Briançon, L., Faucheux, G., and Andromeda, J. 2008. Full-scale experimental study of an embankment reinforced by geosynthetics and rigid piles over soft soil. In Proceedings of the $4^{\text {th }}$ European Geosynthetics Conference, Edinburgh, Scotland, UK, September 2008. CD-ROM

Briançon, L., and Simon, B. 2011. Performance of pile-supported embankment over soft soil: fullscale experiment. Journal of Geotechnical and Geoenvironmental Engineering, 138(4): 551-561

Brown, D. A., Dapp, S. D., Thompson, W. R. and Lazarte, C. A. 2007. Geotechnical Engineering Circular No. 8 - Design and Construction of Continous Flight Auger (CFA) Piles. Washington, D.C., U.S. Department of Transportation - Federal Highway Administration.

BSI. 2010. Code of practice for strengthened/reinforced soils and other fills.

British standard BS8006-1. British Standards Institution, London, UK.

Bui, H. H., Fukagawa, R., Sako, K. and Ohno, S. 2008. Lagrangian meshfree particles method (SPH) for large deformation and failure flows of geomaterial using elastic-plastic soil constitutive model. International Journal for Numerical and Analytical Methods in Geomechanics, 32(12): 1537-1570

Busch, P., Grabe, J., and Gerressen, F. W. 2013. Influence of the installation process of full displacement bored piles on the subsoil. In Proceedings of the Conference on Baltic Piling. Tallin, Estonia. 3-5 September 2012. Taylor and Francis Group, London, U.K. pp. 157-163.

Bustamante, M., and Gianeselli, L. 1993. Design of auger displacement piles from in situ tests. In Proceedings of the 2th international geotechnical seminar on deep foundation on bored and auger piles. Ghent, Belgium. 1 - 4 June 1993. A.A. Balkema, Rotterdam, the Netherlands. pp. 21-34.

Bustamante, M., and Gianeselli, L. 1998. Installation parameters and capacity of screwed piles. In Proceedings of the $3^{\text {rd }}$ International geotechnical seminar on deep foundations on bored and auger piles. Ghent, Belgium. 19 - 21 October 1998. A. A. Balkema, Rotterdam, the Netherlands. pp. 95108. 
Carter, J. P., Randolph, M., and Wroth, C. 1979. Stress and pore pressure changes in clay during and after the expansion of a cylindrical cavity. International Journal for Numerical and Analytical Methods in Geomechanics, 3(4): 305-322

Carter, J. P., Randolph, M. F., and Wroth, P. 1980. Some Aspects of the Performance of Open and Closed-ended Piles. In Proceedings of the International Conference on Numerical Methods in Offshore Piling, ICE, London, pp. 165-170.

Chatte, R. and Lauzon, M. 2011. Embankment Construction Using Controlled Modulus Columns for Nouvelle Autoroute 30 Project in Beauharnois (Qc). In Proceedings of the Pan-American Canadian Geotechnical Society - Geotechnical Conference, Toronto, Ontario, Canada, 2 - 6 October 2011

Collin, J., Watson, C., and Han, J. 2005. Column-supported embankment solves time constraint for new road construction. In Proceedings of the Geo-Frontiers Congress Austin, Texas, United States, 24 - 26 January 2005. American Society of Civil Engineers, pp. 1-10.

Coop, M. R., and Wroth, C. P. 1989. Field studies of an instrumented model pile in clay. Géotechnique, 39(4): 679-696. doi: 10.1680/geot.1989.39.4.679

Eigenbrod, K. D., and Issigonis, T. 1996. Pore-water pressures in soft to firm clay during driving of piles into underlying dense sand. Canadian Geotechnical Journal, 33(2): 209-218

Fok, N., Qui, T., Vincent, P., and Kreminsky, M. 2012. A case study of ground improvement using semi-rigid inclusions for breakwater road bridge. In Proceedings of the International Conference on Ground Improvement and Ground Control, Wollongong, 30 October - 2 November 2012, pp. 629-643.

German Geotechnical Society. 2010. Recommendations for design and analysis of earth structures using geosynthetic reinforcements. German standard

EBGEO 2011. Translation of the 2nd German edition. German Geotechnical Society. Ernst \& Sohn, Germany.

Gibson, R., and Anderson, W. 1961. In situ measurement of soil properties with the pressuremeter. Civil Engineering and Public Works Review, 56(658): 615-618

Gilbert, R. I., and Mickleborough, N. C. 1990. Design of prestressed concrete. CRC Press.

Gniel, J., and Haberfield, C. 2015. Design, construction and performance of a tied-wall embankment supported on concrete column ground improvement. In Proceedings of the International Conference on Geotechnical Engineering: Soil-Structure Interaction, Underground Structures and Retaining Walls St. Petersburg, Russia, June 2014. IOS Press, pp. 18-27.

Gottardi, G., Cavallari, L., and Marchi, M. 2008. Soil fracturing of soft silty clays for the reinforcement of a bell tower foundation. In Proceedings of the $2^{\text {nd }}$ International Workshop on Geotechnics of Soft Soils, Glasgow, Scotland, 3 - 5 September 2008. TayloCRC Press/Balkema, AK Leiden, The Netherlands, pp. 31-41.

Hill, R. 1950. The mathematical theory of plasticity, Clarendon Press, Oxford, UK.

Hsi, J. 2001. Timber-piled embankments over soft ground. In Proceedings of the $15^{\text {th }}$ Interntational Conference on Soil Mechanics and Geotechnical Engineering, Istanbul, Turkey, 27 - 31 Auguest 2001. CRC Press, pp. 2085-2088. 
Iglesia, G. R., Einstein, H. H., and Whitman, R. V. 2013. Investigation of soil arching with centrifuge tests. Journal of Geotechnical and Geoenvironmental Engineering, 140(2). doi: 10.1061/(ASCE)GT.1943-5606.0000998

Jenck, O., Dias, D., and Kastner, R. 2009. Three-Dimensional Numerical Modeling of a Piled Embankment. International Journal of Geomechanics, 9(3): 102-112. doi: 10.1061/(ASCE)15323641(2009)9:3(102)

King, D. J. 2017. The behaviour and performance of geosynthetic reinforced column supported embankments. Ph.D. thesis, Department of Civil Engineering, Monash University, Melbourne, Australia.

King, D. J., Bouazza, A., Gniel, J., and Bui, H. H. 2016. The compressibility, permeability and structured nature of the Coode Island Silt. Australian Geomechanics, 50(2): 45-62

King, D. J., Bouazza, A., Gniel, J., Rowe, K. R., and Bui, H. H. 2017a. Load transfer platform behaviour in embankments supported on semi-rigid columns: implications of the ground reaction curve. Canadian Geotechnical Journal, 54(8):1158-1175. doi: 10.1139/cgj-2016-0406

King, D. J., Bouazza, A., Gniel, J., Rowe, K. R., and Bui, H. H. 2017b. Serviceability design for geosynthetic reinforced column supported embankments. Geotextiles and Geomembranes, 45(4): 261-279. doi: 10.1016/j.geotexmem.2017.02.006

Kitazume, M., and Maruyama, K. 2007. Internal stability of group column type deep mixing improved ground under embankment loading. Soils and Foundations, 47(3): 437-455

Kreyszig, E. 2010. Advanced engineering mathematics. John Wiley \& Sons.

Larisch, M., Arnold, M., Uhlig, M., Schwiteilo, E., Williams, D., and Scheuermann, A. 2013. Stress and displacement monitoring of auger displacement piles. In Proceedings of Pile 2013 - State of the Art of Pile foundations and Case Histories. Bandung, Indonesia. 2-4 June 2013. pp. 1-13.

Larisch, M. D., Nacke, E., Arnold, M., Williams, D., and Scheuermann, A. 2014. Simulation of auger displacement pile installation. International Journal of Geotechnical Engineering, 8(4): 458-462

Lawson, C. R. 2013. Design, Analysis and Performance of Basal Reinforced Embankments Reinforced Soil Course. Melbourne, Australia. 21 February 2013, TenCate Geosynthetics Group.

Lehane, B., and Jardine, R. 1994. Displacement-pile behaviour in a soft marine clay. Canadian Geotechnical Journal, 31(2): 181-191

Liu, H.-L., Chu, J. and Deng, A. 2009. Use of large-diameter, cast in-situ concrete pipe piles for embankment over soft clay. Canadian Geotechnical Journal, 46(8): 915-927

Liu, H., Ng, C. W., and Fei, K. 2007. Performance of a geogrid-reinforced and pile-supported highway embankment over soft clay: case study. Journal of Geotechnical and Geoenvironmental Engineering, 133(12): 1483-1493

Marchi, M., Gottardi, G., and Soga, K. 2013. Fracturing Pressure in Clay. Journal of Geotechnical and Geoenvironmental Engineering, 140(2)

Massarsch, K. R., and Broms, B. B. 1977. Fracturing of soil caused by pile driving in clay. In Proceedings of the $9^{\text {th }}$ International Conference on Soil Mechanics and Foundation Engineering, Tokyo, Japan, 10 - 15 July 1977. Kluwer Academic pp. 197-200. 
Masse, F., Brockbank, B., and Pearlman, S. 2004. CMC: potential application to Canadian soils with a new trend in ground improvement. In Proceedings of the Geo-Quebec 2004, Quebec, Canada, 22 27 October 2004, Session 4F. pp. 32 - 39.

Mikkelsen, P. E. 2002. Cement-bentonite grout backfill for borehole instruments. Geotechnical News, 20(4): $38-42$

Mikkelsen, P. E. 2003. Advances in inclinometer data analysis. In Proceedings of the $6^{\text {th }}$ International Symposium on Field Measurements in Geomechanics, Oslo, Norway, 15 - 18 September 2003

NeSmith, W. M. 2002. Static Capacity Analysis of Augered, Pressure-Injected Displacement Piles. In Proceedings of the International Deep Foundations Congress Orlando, Florida, United States 14 16 February 2002. American Society of Civil Engineers, Reston, VA pp. 1174-1186.

NeSmith, W. M., and Fox, J. 2009. Practical considerations for design and installation of drilled displacement piles. In Proceedings of the Contemporary Topics in Deep Foundations, Orlando, Florida, USA, 15 - 19 March 2009. ASCE, pp. 438-446.

NeSmith, W. M., and NeSmith, W. M. 2006. Anatomy of a data acquisition system for drilled displacement piles. Proceedings of the GeoConGress 2006. Atlanta, Georgia, USA. 26 February 1 March 2006. American Society of Civil Engineers, Reston, Virginia, USA. pp. 1-6.

O’Neill, M. W., Hawkins, R. A., and Audibert, J. M. 1982. Installation of pile group in overconsolidated clay. Journal of the Geotechnical Engineering Division, 108(11): 1369-1386

Ooi, P., and Ramsey, T. 2003. Curvature and bending moments from inclinometer data. International Journal of Geomechanics, 3(1): 64-74

Park, S., Roberts, L. A., and Misra, A. 2012. Design methodology for axially loaded auger cast-inplace and drilled displacement piles. Journal of Geotechnical and Geoenvironmental Engineering, 138(12): 1431-1441

Piscsalko, G., and Likins, G. 2004. Automatic Inspection Control of Augercast Piles. In Proceedings of the $83^{\text {rd }}$ Transportation Research Board Annual Meeting. Washington, D.C. USA. 11-15 January 2004. pp. 11-16.

Plomteux, C., and Porbaha, A. 2004. CMC foundation system for embankment support. In Proceedings of the Geosupport Conference, Orlando, Florida, United States, December 29 - 31, 2004. American Society of Civil Engineers

Poulos, H. 1994. Effect of pile driving on adjacent piles in clay. Canadian Geotechnical Journal, 31(6): 856-867

Prezzi, M., and Basu, P. 2005. Overview of construction and design of auger cast-in-place and drilled displacement piles. In Proceedings of the $30^{\text {th }}$ Annual Conference on Deep Foundations, Chicago, Illinois, USA, pp. 497-512.

Pucker, T., and Grabe, J. 2012. Numerical simulation of the installation process of full displacement piles. Computers and Geotechnics, 45: 93-106. 10.1016/j.compgeo.2012.05.006

Qiu, G., Henke, S., and Grabe, J. 2011. Applications of coupled Eulerian-Lagrangian method to geotechnical problems with large deformations. Computers and Geotechnics, 38: 30-39. doi: 10.1016/j.compgeo.2010.09.002

Raithel, M., Kirchner, A., and Kempfert, H. 2008. Pile-supported embankments on soft ground for a high speed railway-Load Transfer, Distribution and Concentration by different construction 
methods. In Proceedings of the Advances in Transportation Geotechnics, Nottingham, UK, 25 27 August 2008. CRC Press, pp. 401-407.

Randolph, M. 2003. Science and empiricism in pile foundation design. Geotechnique, 53(10): 847875

Randolph, M. F., Carter, J., and Wroth, C. 1979. Driven piles in clay-the effects of installation and subsequent consolidation. Geotechnique, 29(4): 361-393

Randolph, M. F., and Wroth, C. 1979. An analytical solution for the consolidation around a driven pile. International Journal for Numerical and Analytical Methods in Geomechanics, 3(3): 217-229

Rogbeck, Y., Alen, C., Gunilla, F., Kjeld, A., Oden, K., Rathmayer, H., Watn, A., and Oiseth, E. 2004. Nordic guidelines for reinforced soils and fills. Nordic Geotechnical Societies.

Sagaseta, C., and Whittle, A. J. 2001. Prediction of ground movements due to pile driving in clay. Journal of Geotechnical and Geoenvironmental Engineering, 127(1): 55-66

Satibi, S., Leoni, M., Vermeer, P., and van der Meij, R. 2010. On the numerical analysis of piled embankments. In Proceedings of the Geotechnics of Soft Soils: Focus on Ground Improvement: Proceedings of the $2^{\text {nd }}$ International Workshop held in Glasgow, Scotland, 3 - 5 September 2008. CRC Press, 353-358.

Shen, S.-L. and Miura, N. 1999. Soil fracturing of the surrounding clay during deep mixing column installation. Soils and Foundations, 39(5): 13-22

Shen, S.-L., Miura, N., and Koga, H. 2003. Interaction mechanism between deep mixing column and surrounding clay during installation. Canadian Geotechnical Journal, 40(2): 293-307

Shen, S.-L. M., Han, J., and Koga, H. 2004. Evaluation of property changes in surrounding clays due to installation of deep mixing columns. In Proceedings of the $3^{\text {rd }}$ International Conference on Grouting and Ground Treatment New Orleans, Louisiana, United States 10 - 12 February 2003. American Society of Civil Engineers, Reston, VA

Soga, K., Ng, M., and Gafar, K. 2005. Soil fractures in grouting. In Proceedings of the $11^{\text {th }}$ International Conference on Computer Methods and Advances in Geomechanics, Torino, Italy 19 - 24 June 2005. Patron Editore, pp. 397-406.

Suleiman, M. T., Ni, L., Davis, C., Lin, H., and Xiao, S. 2015. Installation Effects of Controlled Modulus Column Ground Improvement Piles on Surrounding Soil. Journal of Geotechnical and Geoenvironmental Engineering, 142(1): doi: 10.1061/(ASCE)GT.1943-5606.0001384

van Duijnen, P., van Eekelen, S., and van der Stoel, A. 2010. Monitoring of a railway piled embankment. In Proceedings of the $9^{\text {th }}$ International Geosynthetics Conference, Guarujá, Brazil, 23-27 May 2010. Brazilian Geosynthetics Society pp. 1461-1464.

van Eekelen, S. J. M., Bezuijen, A., and Alexiew, D. 2010. The Kyoto road piled embankment: 3.5 years of measurements. In Proceedings of the $9^{\text {th }}$ International Conference on Geosynthetics, Guaruja, Brazil, 23 - 27 May 2010, pp. 1941-1944.

Więckowski, Z. 2004. The material point method in large strain engineering problems. Computer Methods in Applied Mechanics and Engineering, 193(39): 4417-4438

Wong, P., and Muttuvel, T. 2012. Design of embankments supported on controlled modulus columns. International Journal of Geotechnical Engineering 6(2): doi: 10.3328/IJGE.2012.06.02.207-213 
Xing, H., Zhang, Z., Liu, H., and Wei, H. 2014. Large-scale tests of pile-supported earth platform with and without geogrid. Geotextiles and Geomembranes, 42(6): 586-598

Yu, H.-S. 2013. Cavity expansion methods in geomechanics. Springer Science \& Business Media.

Yu, H., and Carter, J. 2002. Rigorous similarity solutions for cavity expansion in cohesive-frictional soils. International Journal of Geomechanics, 2(2): 233-258

Zhang, J., Zheng, J.-J., Chen, B.-G., and Yin, J.-H. 2013. Coupled mechanical and hydraulic modeling of a geosynthetic-reinforced and pile-supported embankment. Computers and Geotechnics, 52: 28-37 


\section{Figure captions}

Fig. 1. Typical column installation for North Dynon embankment (modified from Yu 2013)

Fig. 2. Axisymmetric time-dependent cylindrical cavity expansion solutions; (a) Pore water pressure and (b) radial displacement

Fig. 3. North Dynon embankment - plan view

Fig. 4. Embankment cross section - area No. 2

Fig. 5. Long-term piezometer data and applied embankment stress acting on Coode Island Silt

Fig. 6. Columns installed near area No. 1 piezometer

Fig. 7. Response of piezometer to column installation

Fig. 8. Pore water pressure development based on cylindrical cavity expansion theory

Fig. 9. Layout of columns - Inclinometer No. 2.

Fig. 10. Transverse-axis displacement during Stage 1 works - Inclinometer No. 2

Fig. 11. Lateral movement at $1.5 \mathrm{~m}$ depth (Plan View) - Inclinometer No. 2

Fig. 12. Long-term data - Inclinometer No. 2

Fig. 13. Normalized vertical settlement of gabion wall and arching development

Fig. 14. Limit states associated with lateral embankment deformation

Fig. 15. Post-construction survey monitoring - long-term lateral displacement vectors

Fig. 16. Long-term lateral displacement - Inclinometer No. 2

Fig. 17. Long-term tiltmeter data

Fig. 18. Lateral displacement of embankment and pwp dissipation during the post-construction period

Fig. 19. Inferred loading on column $\mathrm{C} 15$ during construction phase; (a) displacement (b) bending moment profile and long-term (c) displacement (d) bending moment profile

Fig. 20. (a) Lateral displacement due to installation of columns C15 and D10 and equivalent bending moment profiles for; (b) $\mathrm{C} 15$ and (c) D10. 
Table 1. Stage 1 timeline - Inclinometer No. 2

\begin{tabular}{|c|c|c|c|c|}
\hline Activity & Time (hours:minutes) & Phase no. & $r(\mathbf{m})$ & $r / D$ \\
\hline Baseline Reading & & \multirow{4}{*}{ Phase 1} & & \\
\hline D17 - 15 March 11:13 am & $3: 27$ & & 4.69 & 10.4 \\
\hline D14 - 15 March 12:38 pm & $2: 02$ & & 4.66 & 10.4 \\
\hline Inclio reading & & & & \\
\hline D15 - 18 March 11:16 am & 7 days $23: 32$ & \multirow{4}{*}{ Phase 2} & 3.97 & 8.8 \\
\hline C17 - 18 March 11:56 am & 7 days $22: 52$ & & 3.20 & 7.1 \\
\hline C14 - 18 March 12:25pm & 7 days $22: 23$ & & 3.60 & 8.0 \\
\hline \multicolumn{4}{|l|}{ Inclio reading } & \\
\hline C15 - 27 March 9:23 am & $3: 37$ & \multirow{2}{*}{ Phase $3 \mathrm{a}$} & 2.04 & 4.5 \\
\hline Inclio reading & & & & \\
\hline Inclio reading & & Phase $3 b$ & & \\
\hline
\end{tabular}


Table 2. Long-term Inclinometer No. 2 readings

\begin{tabular}{|c|c|c|}
\hline Date and time & $\begin{array}{c}\text { Days } \\
\text { elapsed }\end{array}$ & Phase \\
\hline 13 March 2013 & -51 & Baseline \\
\hline $\begin{array}{l}14-27 \text { March } \\
\text { (four readings) }\end{array}$ & -50 to -37 & $\begin{array}{l}\text { Stage } 1 \text { works } \\
\text { (installation) }\end{array}$ \\
\hline 3 April & -30 & \multirow{8}{*}{$\begin{array}{l}\text { Stage } 1 \text { works } \\
\text { (equilibration) }\end{array}$} \\
\hline 17 May & 14 & \\
\hline 21 May & 18 & \\
\hline 28 May & 25 & \\
\hline 4 June & 32 & \\
\hline 20 June & 48 & \\
\hline 25 June & 53 & \\
\hline 5 July & 63 & \\
\hline $\begin{array}{l}5 \text { to } 14 \text { July } \\
\text { (no readings) }\end{array}$ & 63 to 71 & $\begin{array}{c}\text { Stage 3a works } \\
\text { (installation) }\end{array}$ \\
\hline 23 July & 81 & $\begin{array}{l}\text { Stage 3a works } \\
\text { (equilibration) }\end{array}$ \\
\hline $\begin{array}{l}11 \text { to } 17 \text { Sept. } \\
\text { (no readings) }\end{array}$ & 131 to 137 & $\begin{array}{c}\text { Stage } 3 b \text { works } \\
\text { (installation) }\end{array}$ \\
\hline 10 October & 160 & \multirow{2}{*}{$\begin{array}{l}\text { Post-construction } \\
\text { (equilibration) }\end{array}$} \\
\hline 14 May 2015 & 741 & \\
\hline
\end{tabular}




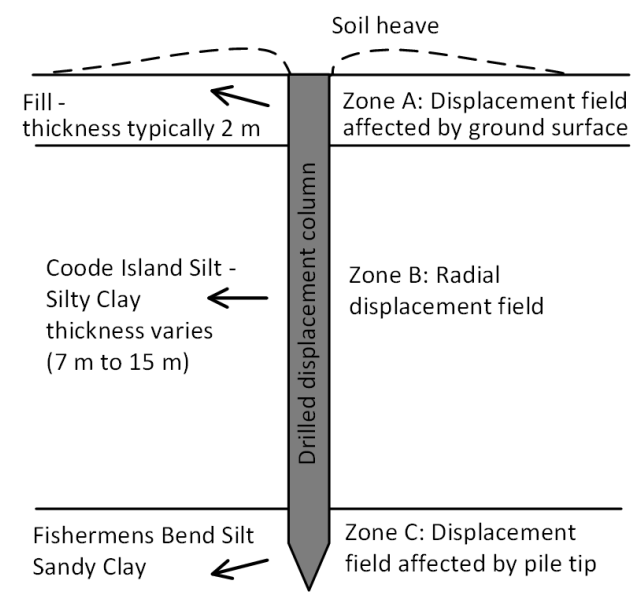

Fig. 1. Typical column installation for North Dynon embankment (modified from Yu, 2013) 
(a) Pore water pressure field

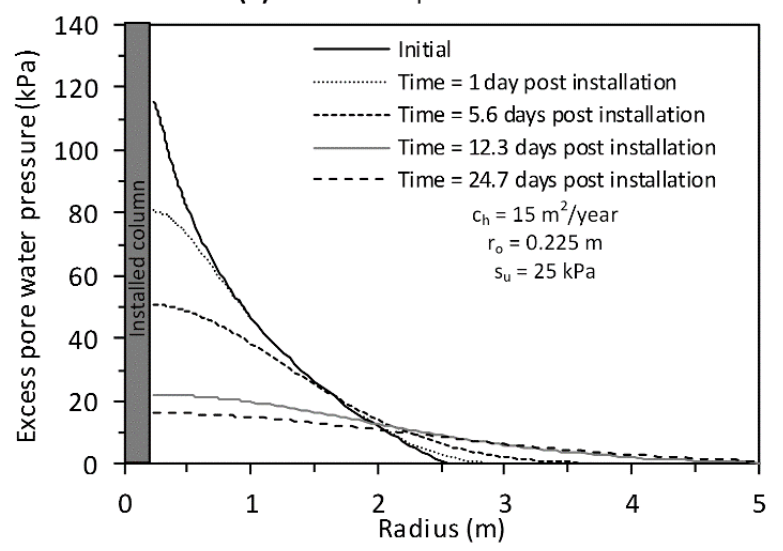

(b) Radial displacement field

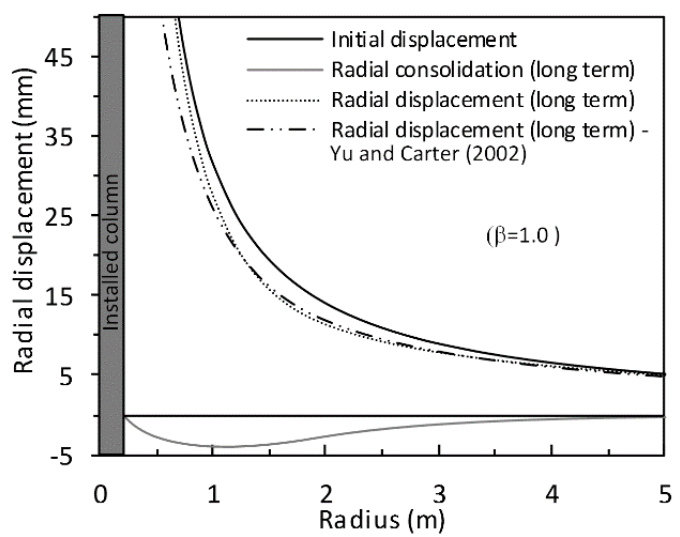

Fig. 2. Axisymmetric time-dependent cylindrical cavity expansion solutions; (a) Pore water pressure and (b) radial displacement 


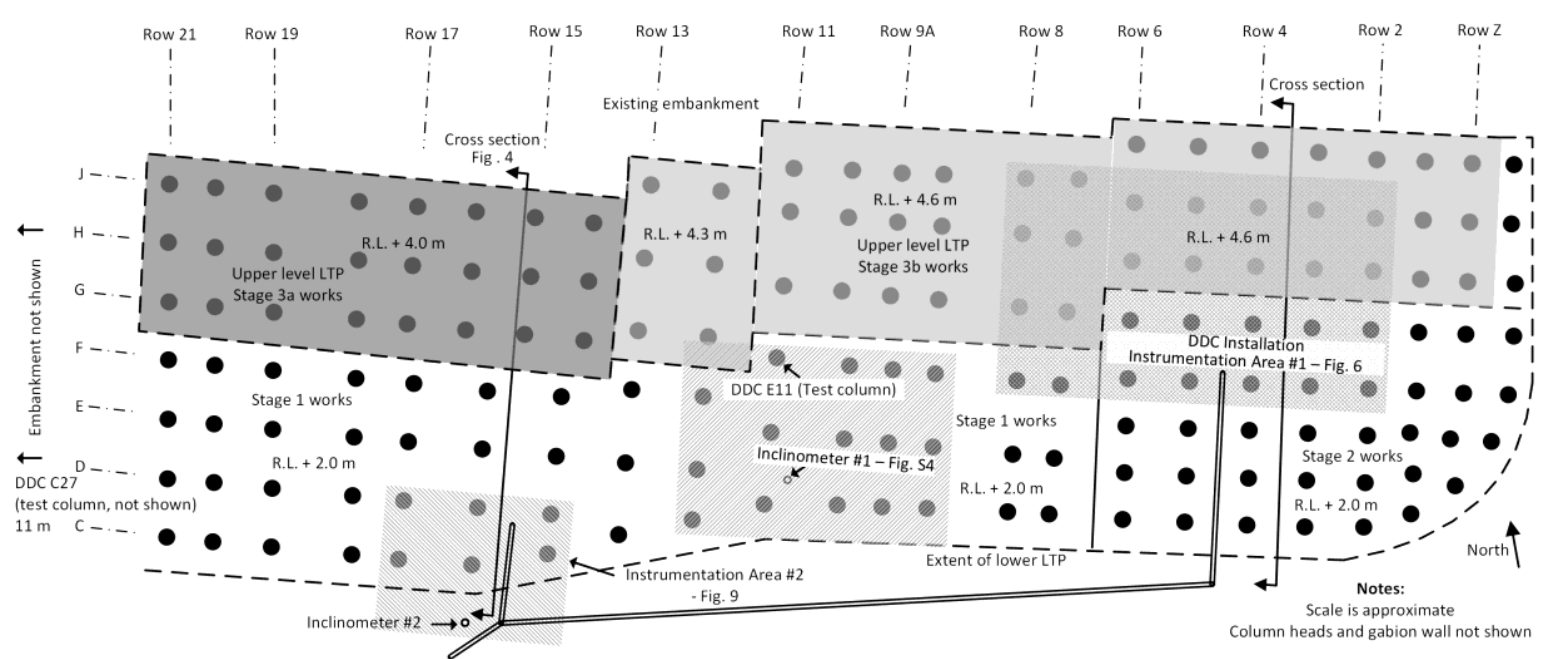

Fig. 3. North Dynon embankment - plan view 


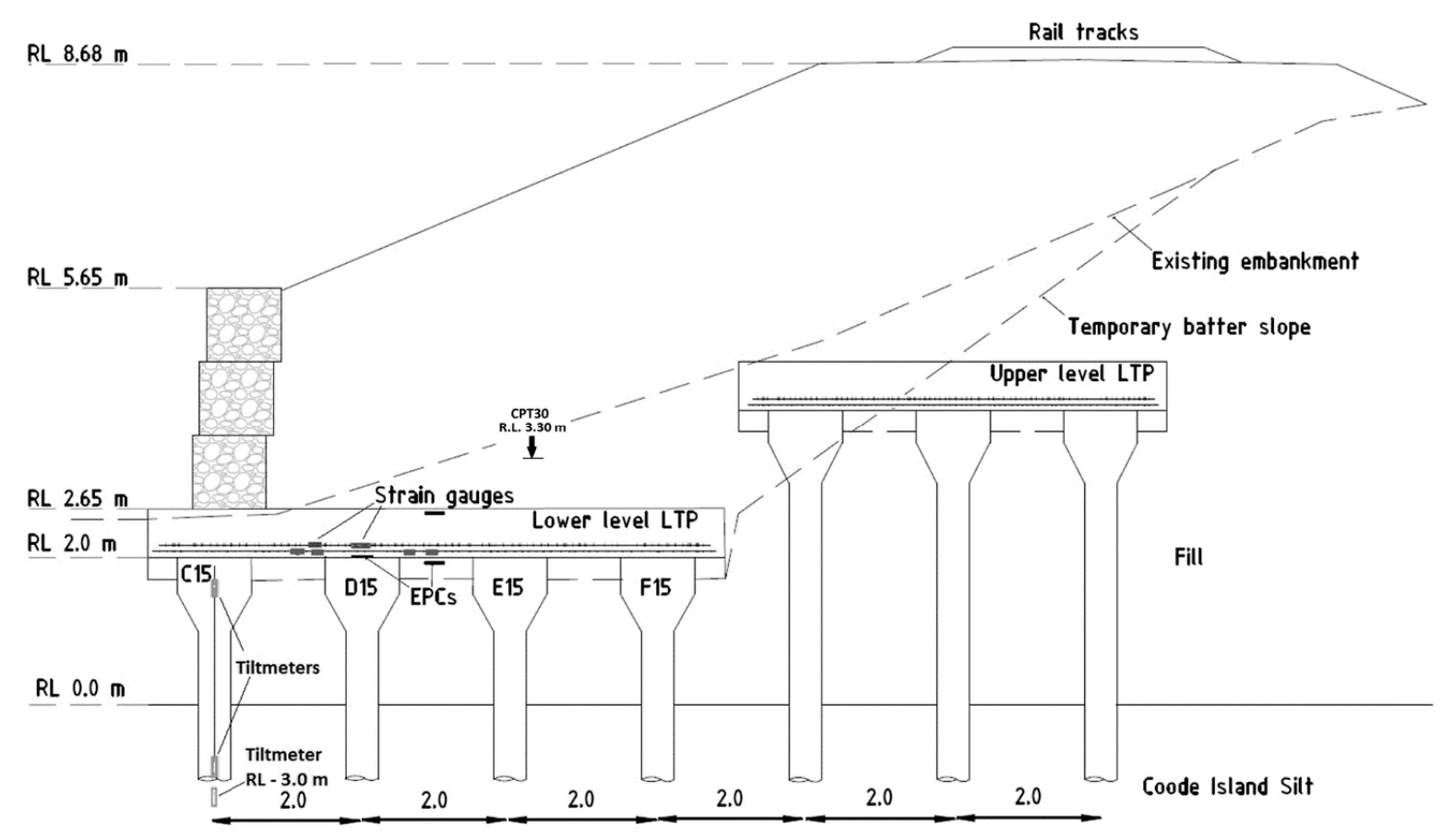

Fig. 4. Embankment cross section - Area \#2 


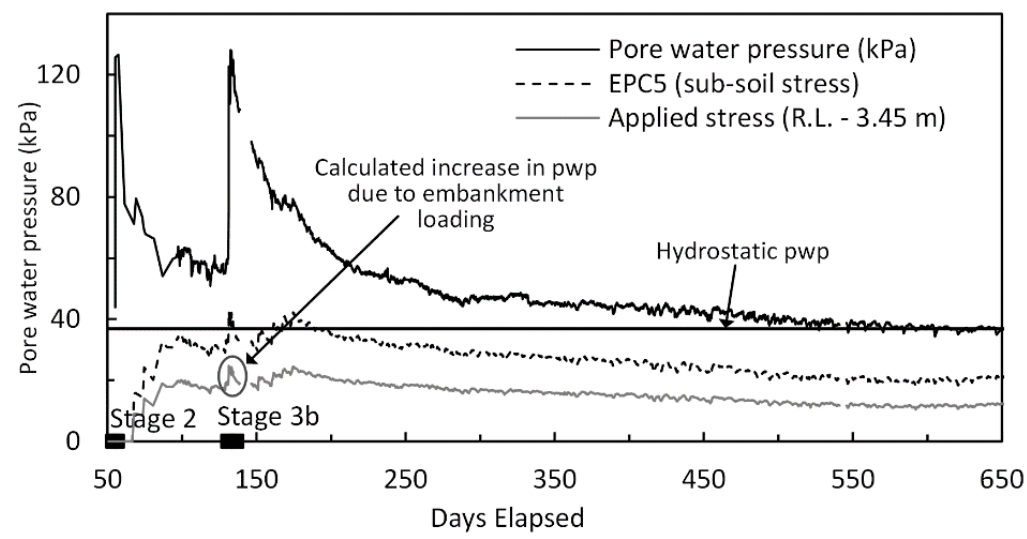

Fig. 5. Long-term piezometer data and applied embankment stress acting on Coode Island Silt 


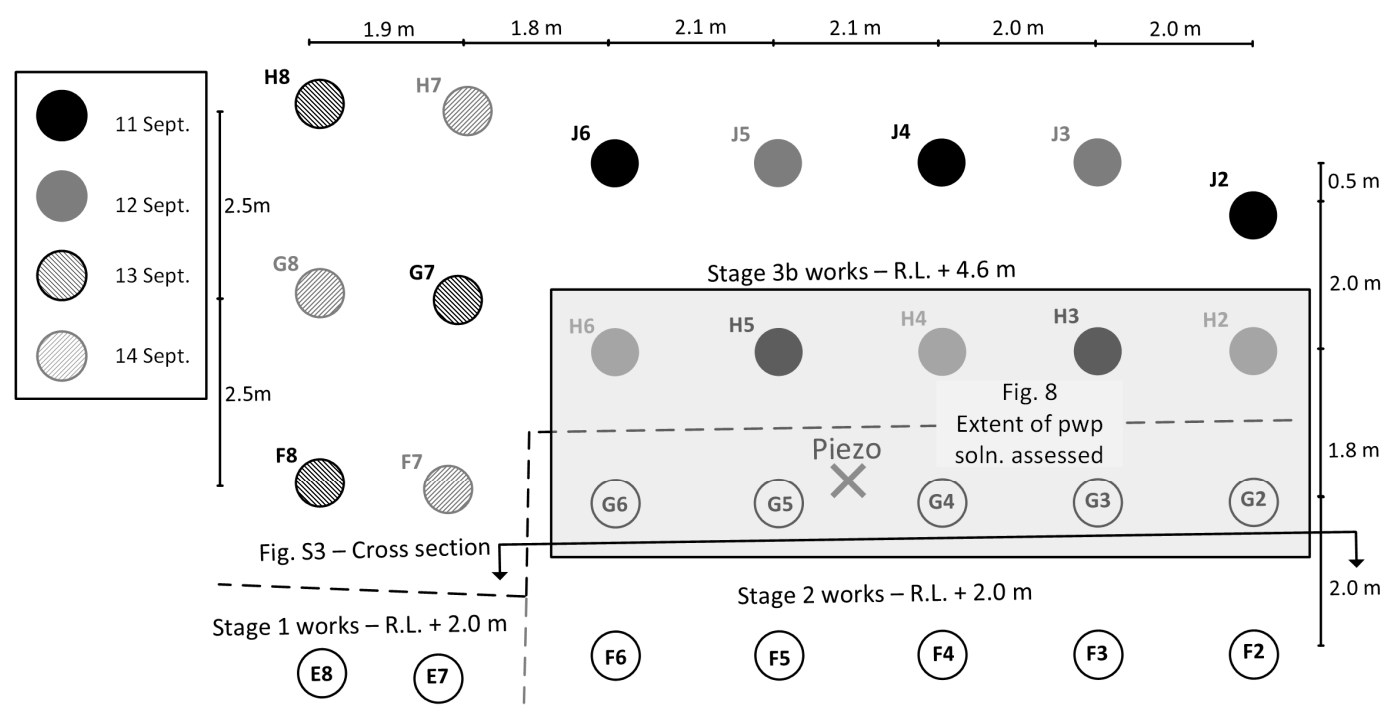

Fig. 6. Columns installed near Area \#1 piezometer 


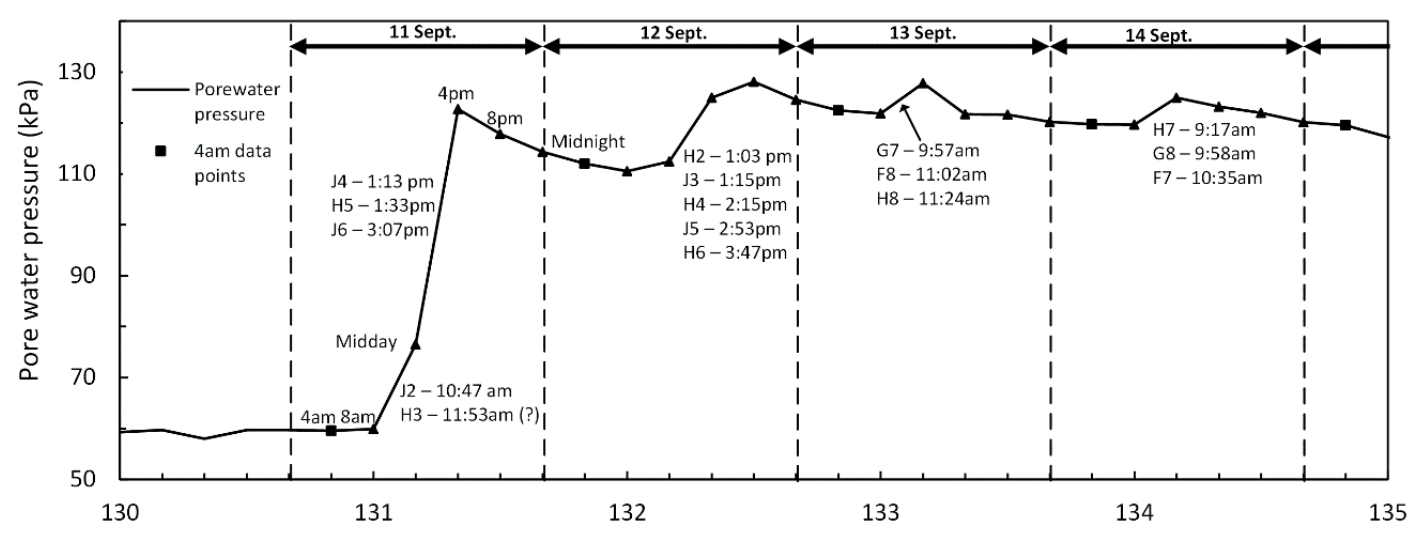

Fig. 7. Response of piezometer to column installation 

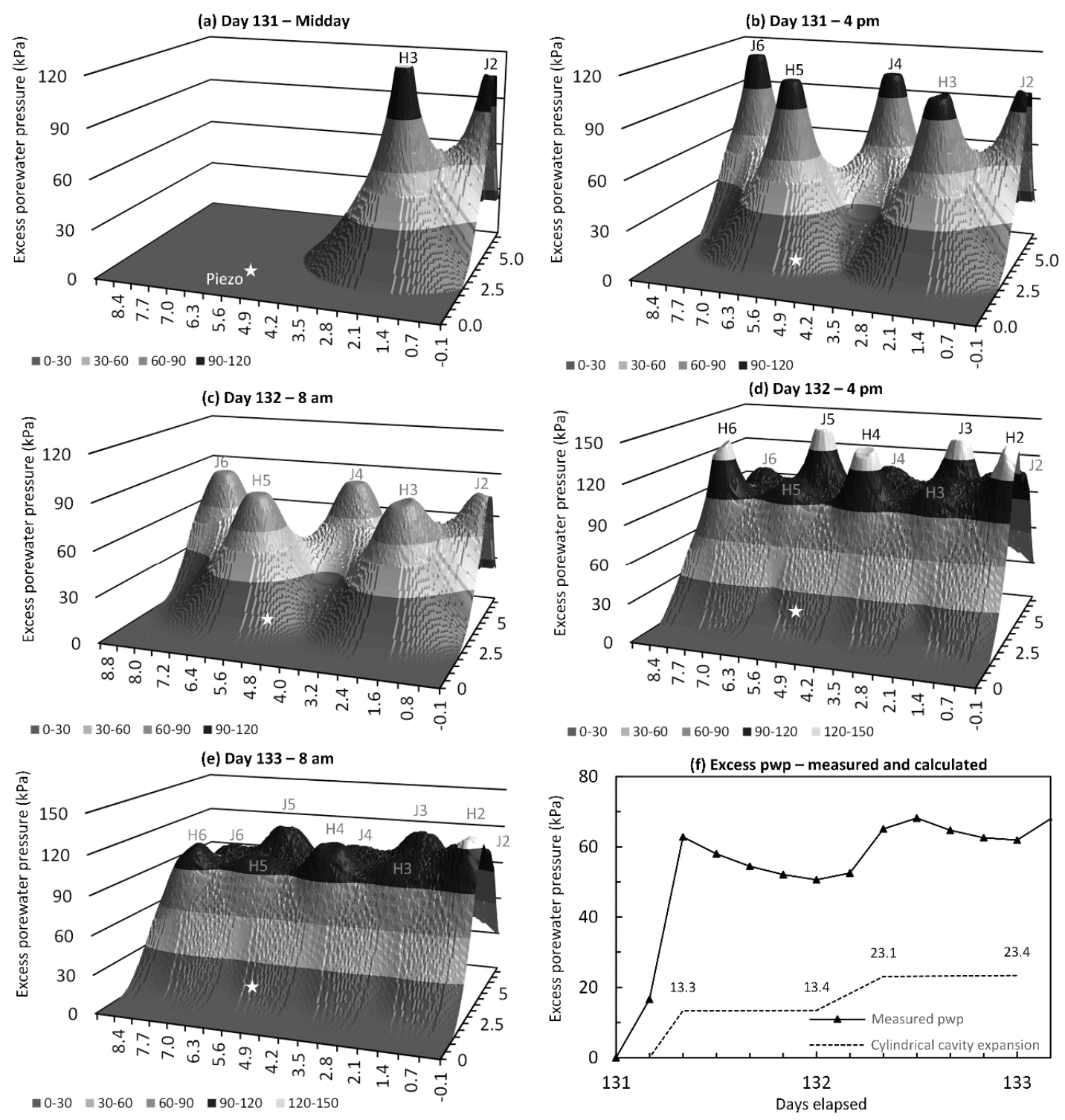

Fig. 8. Pore water pressure development based on cylindrical cavity expansion theory 


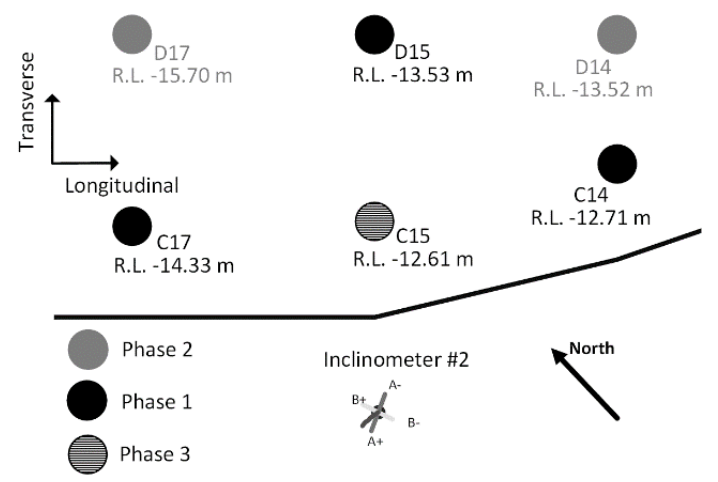

Fig. 9. Layout of columns - Inclinometer \#2. 


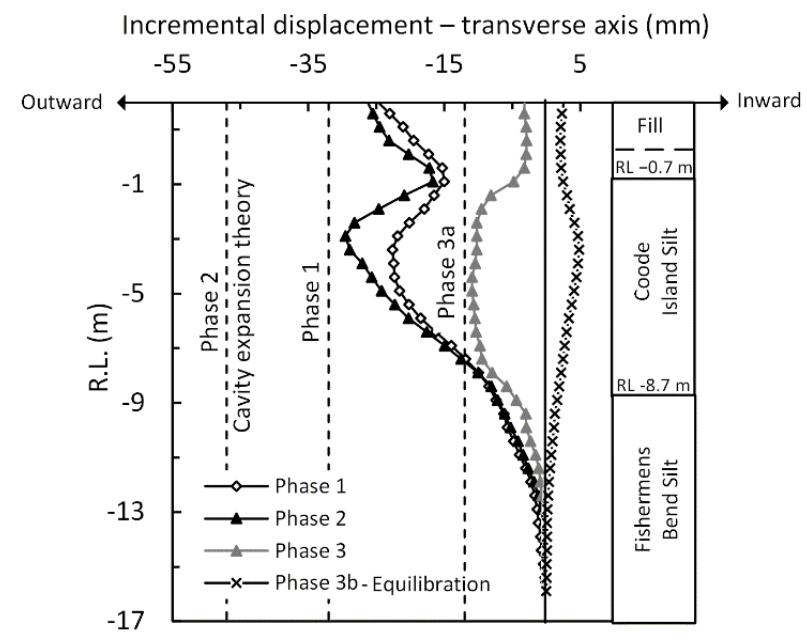

Fig. 10. Transverse-axis displacement during Stage 1 works - Inclinometer \#2 


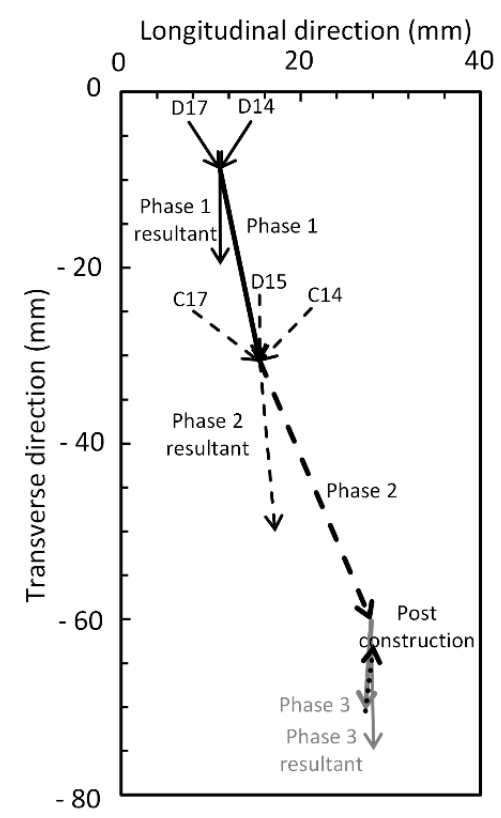

Fig. 11. Lateral movement at $1.5 \mathrm{~m}$ depth (Plan View) - Inclinometer \#2 


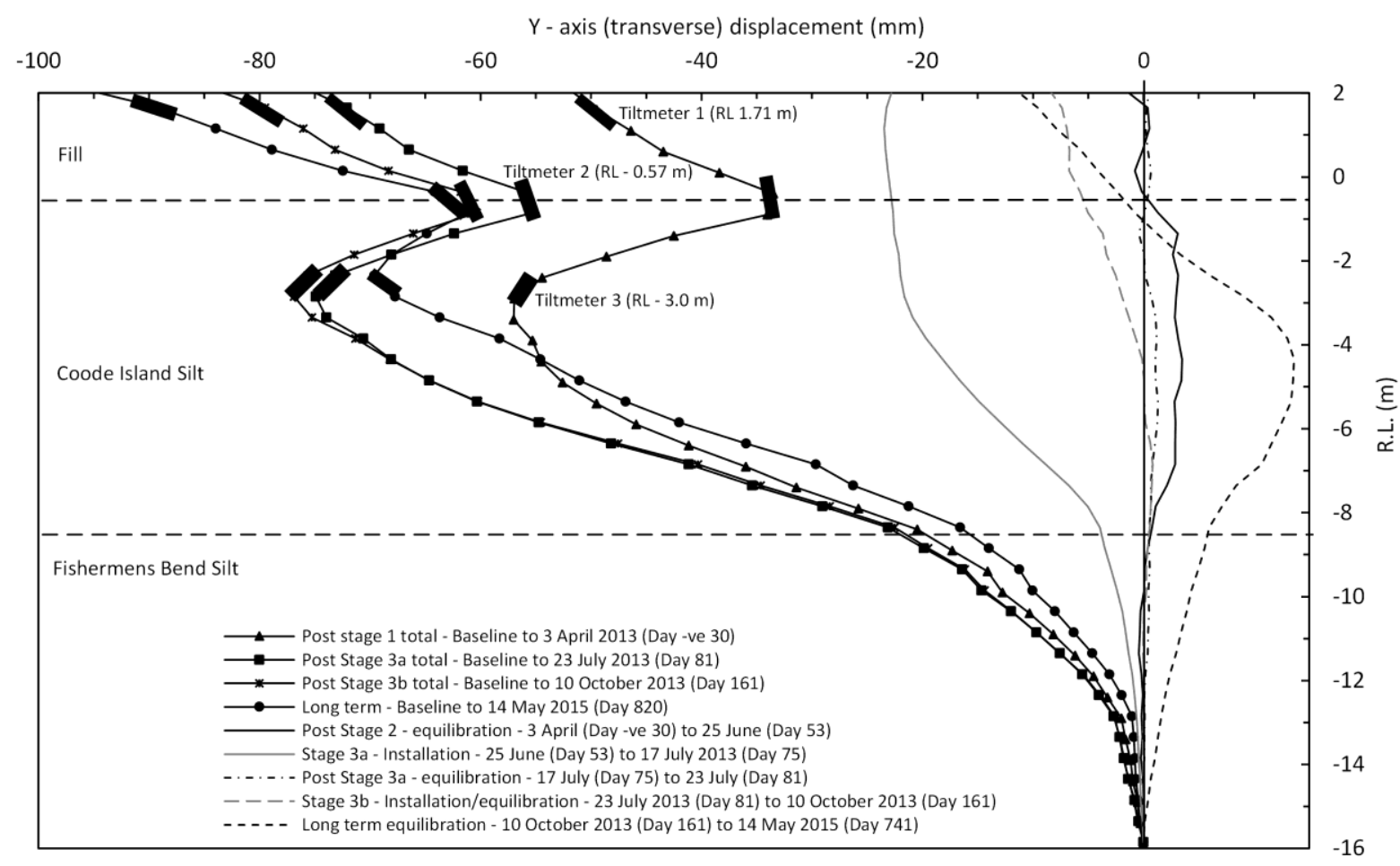

Fig. 12. Long-term data - Inclinometer \#2 


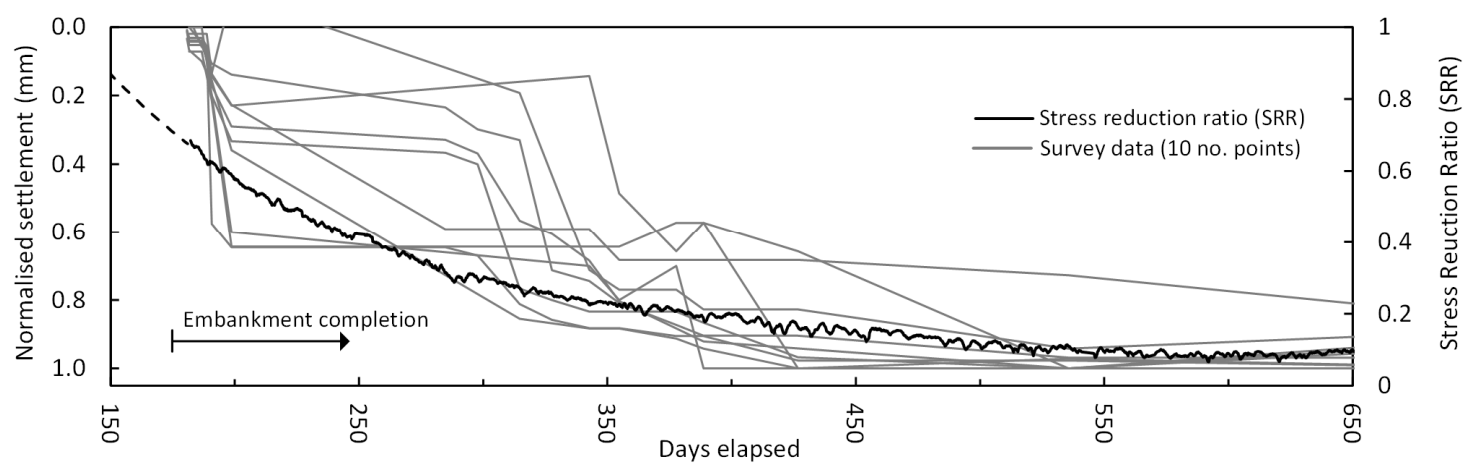

Fig. 13. Normalised vertical settlement of gabion wall and arching development 


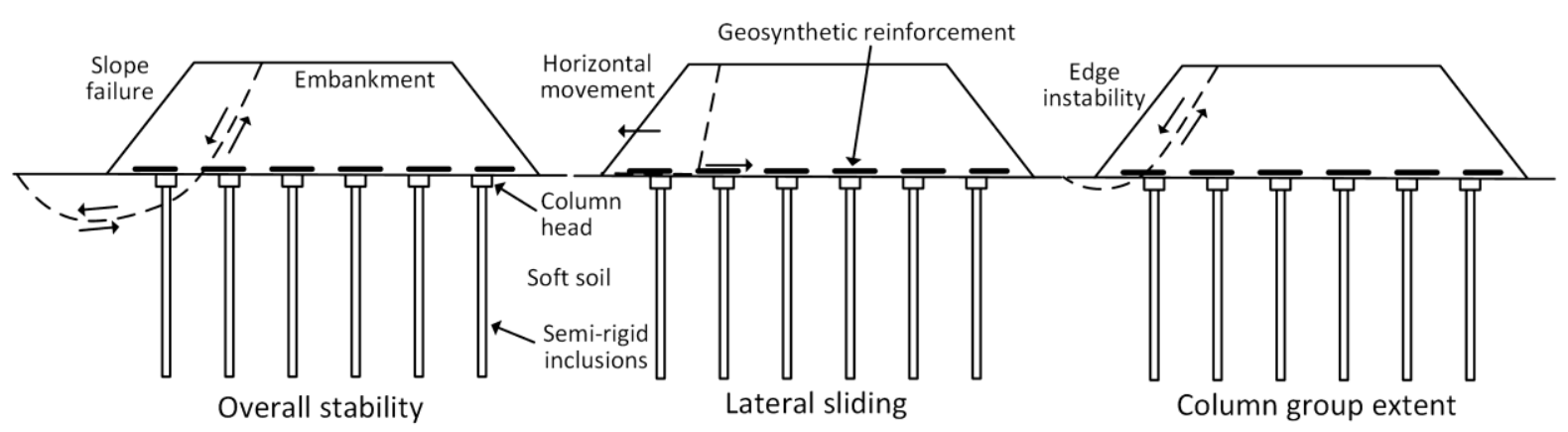

Fig. 14. Limit states associated with lateral embankment deformation 


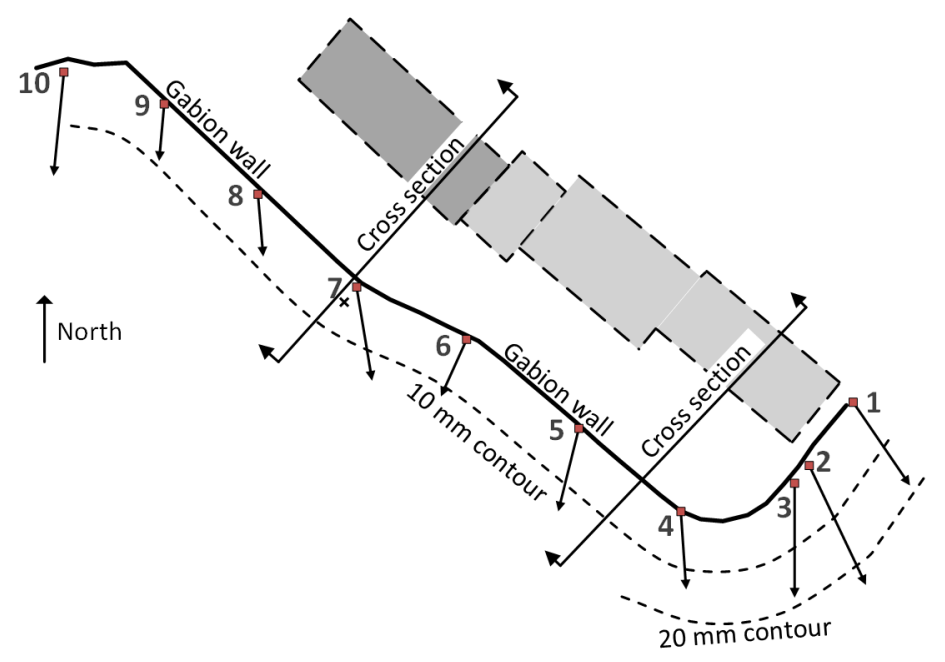

Fig. 15. Post-construction survey monitoring - long-term lateral displacement vectors 


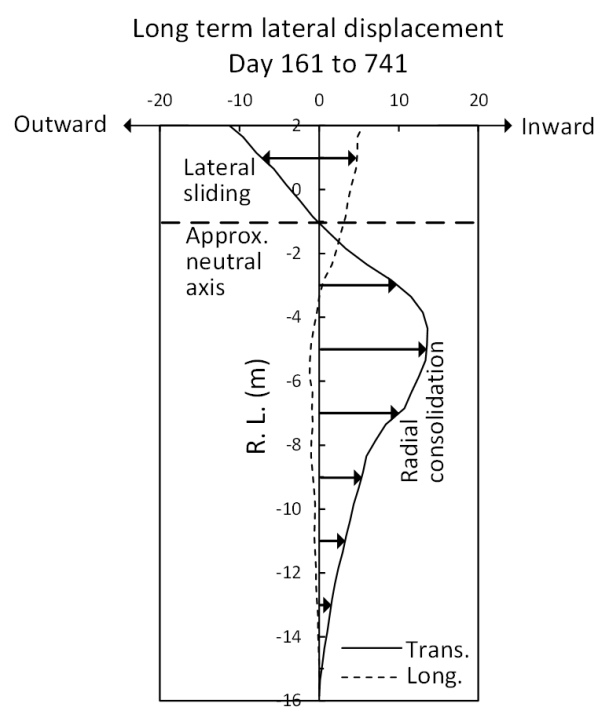

Fig. 16. Long-term lateral displacement - Inclinometer \#2 


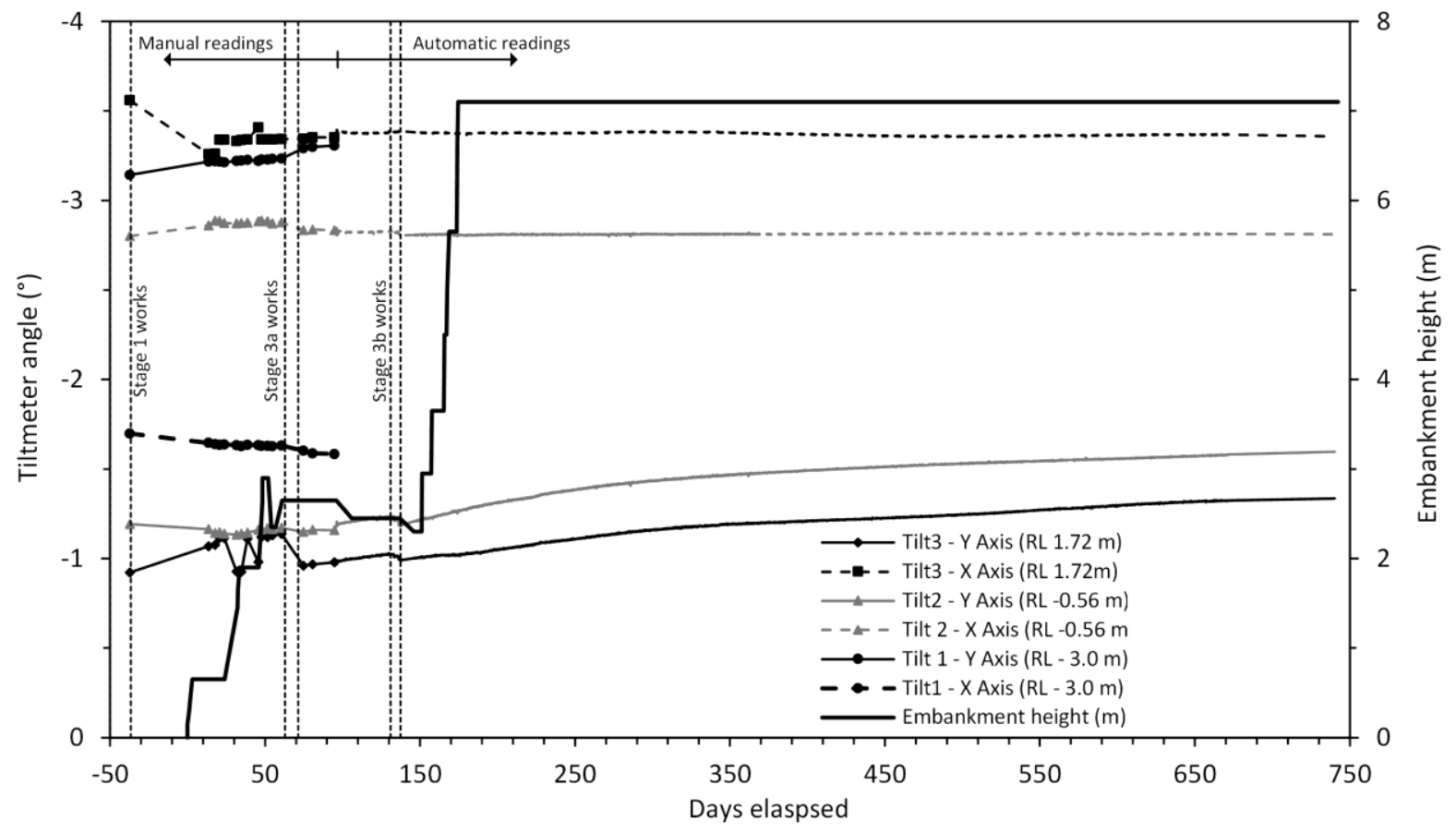

Fig. 17. Long-term tiltmeter data 


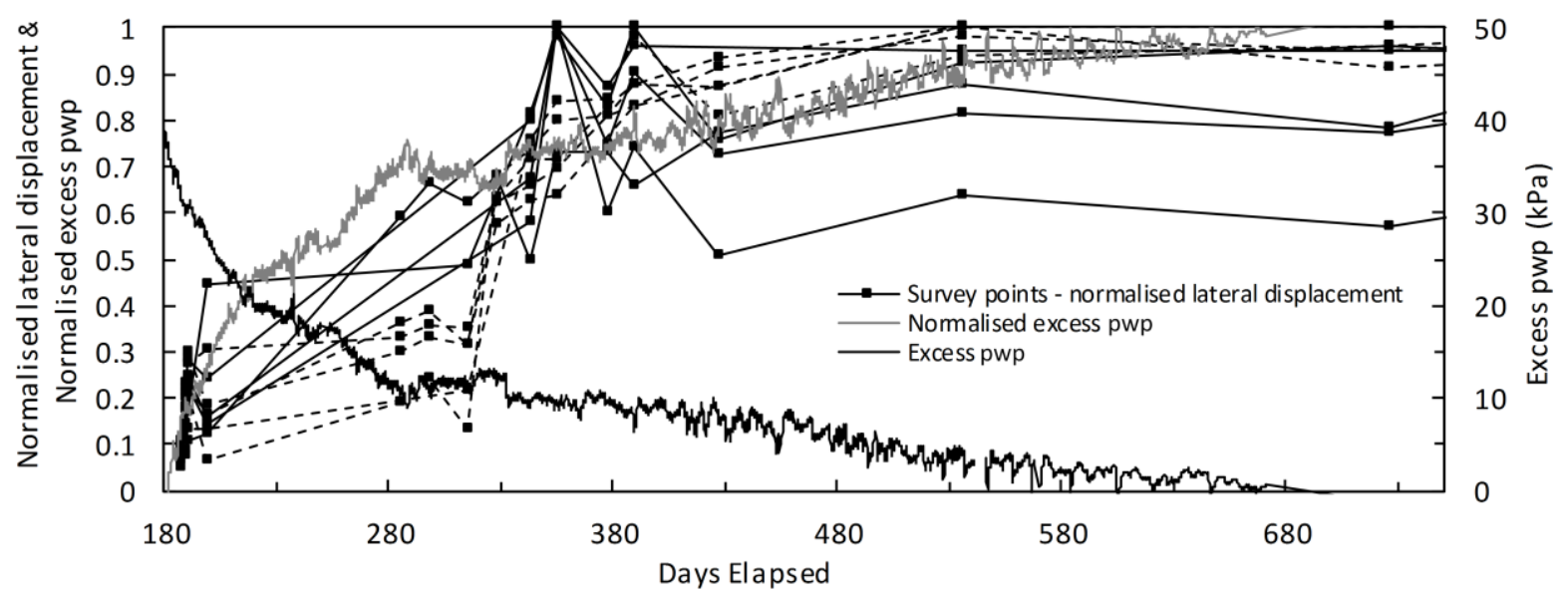

Fig. 18. Lateral displacement of embankment and pwp dissipation during the post-construction period 
Installation to end of construction (day 161) Ground improvement works

(a)

(b)

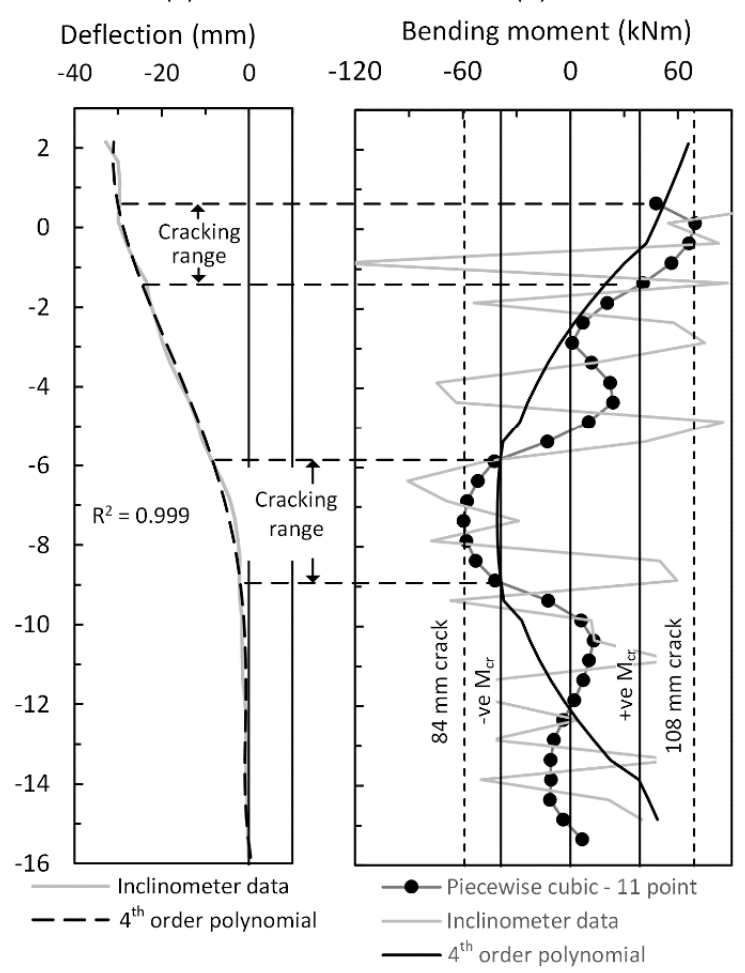

Installation to day 741

Ground improvement works + lateral sliding + equilibration

(c)

(d)

Fig. 19. Inferred loading on column $\mathrm{C} 15$ during construction phase; (a) displacement (b) bending moment profile and long term (c) displacement (d) bending moment profile 
Installation of columns - lateral displacement and bending moment profiles

(a)

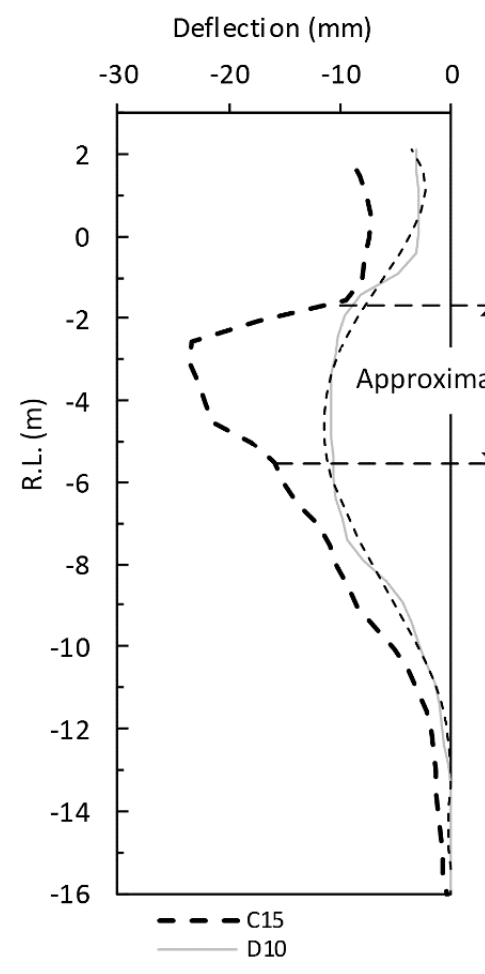

(a) Bending moment $(\mathrm{kNm})$

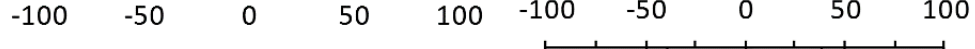

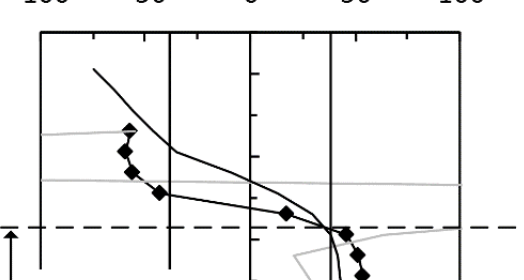

te cracking range

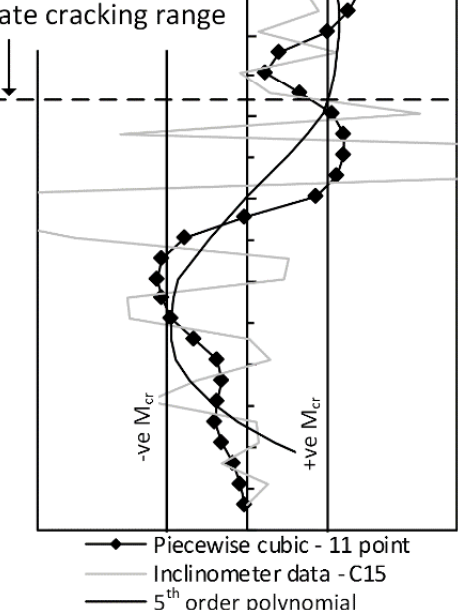

Bending moment $(\mathrm{kNm})$

(c)

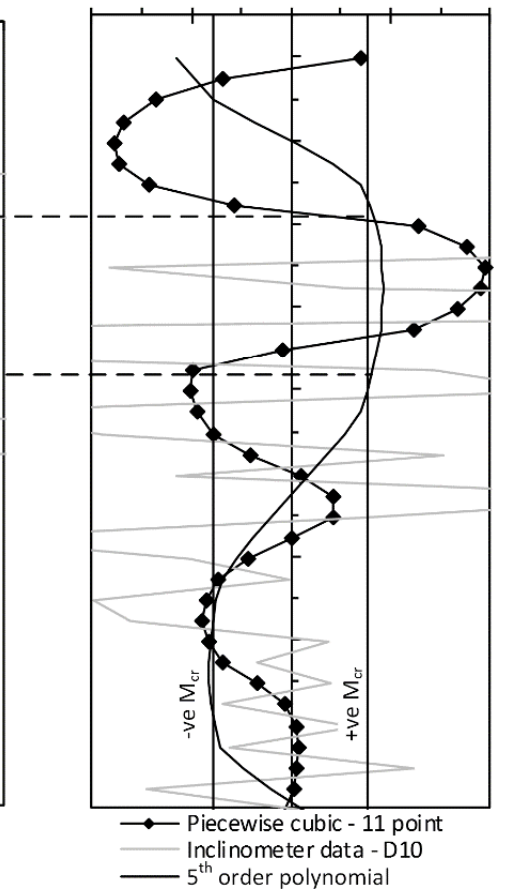

Fig. 20. (a) Lateral displacement due to installation of columns C15 and D10 and equivalent bending moment profiles for (b) C15 and (c) D10 


\section{A geosynthetic reinforced column supported embankment and the role of ground improvement installation effects}

Daniel J. King, Abdelmalek Bouazza, Joel R. Gniel, R. Kerry Rowe, Ha H. Bui

Supplementary data

This supplementary section includes:

1) An overview and derivation of the cylindrical cavity expansion solutions for the installation of a full displacement column/pile;

2) Additional data describing the porewater pressure (pwp) response and lateral deformation as measured by Inclinometer No. 1 as well as the collapse of arching due to the installation of nearby columns; and

3) Further information relating to the assessment of bending moments in drilled displacement columns (DDCs)

\section{Cylindrical cavity expansion theory}

The cylindrical cavity expansion solutions developed by Randolph et al. (1979) describe the excess pwp and displacement field for the soil mass surrounding a driven pile and is summarized below. The cavity expansion solution relies on the assumption that the axisymmetric deformation occurs in an elastic-perfectly plastic material, therefore the only degree of freedom permitted is in the radial direction. The geometric parameters used in the analysis are defined in Fig. S1 along with an initial excess pwp distribution described below.

Based on the axisymmetric conditions the governing equations are developed in cylindrical co-ordinates in terms of the radial, circumferential and vertical stresses $\left(\sigma_{\mathrm{r}}, \sigma_{\theta}\right.$ and $\sigma_{\mathrm{z}}$ respectively) and strains $\left(\varepsilon_{\mathrm{r}}, \varepsilon_{\theta}\right.$ and $\varepsilon_{\mathrm{z}}$ respectively) using Hooke's law, radial equilibrium and continuity of the volumetric strain rate along with Darcy's law to describe the flow of excess pwp due to the pwp gradient. The first governing equation describing the variation of excess pwp $(u)$ with time $(t)$ is:

$$
\frac{\partial u}{\partial t}=c\left[\frac{1}{r} \frac{\partial}{\partial r}\left(r \frac{\partial u}{\partial r}\right)\right]+g(t)=c \nabla^{2} u+g(t)
$$

$$
c=\frac{k}{\gamma_{\mathrm{w}}} G^{*}=\frac{k}{\gamma_{\mathrm{w}}} \frac{2 G(1-v)}{(1-2 v)}
$$

where $r$ is the radius, $g(t)$ is a constant of integration, $c$ is the coefficient of consolidation which is defined in the usual manner with $k$ being the (radial) permeability of the soil, $\gamma_{\mathrm{w}}$ the unit weight of water, $G$ the shear modulus and $v$ is Poisson's ratio. With the exception of the constant of integration the governing equation for pwp is identical to Terzaghi's one dimensional consolidation equation.

The second governing equation describing the variation of radial displacement $\xi$ due to consolidation at radius $r$ is:

$$
\frac{\partial \xi}{\partial t}=\frac{k}{\gamma_{\mathrm{w}}} \frac{d u_{0}}{d r}+c\left\{\frac{\partial}{\partial r}\left[\frac{1}{r} \frac{\partial}{\partial r}(r \xi)\right]\right\}-\frac{f(t)}{r}
$$

where $f(t)$ is a constant of integration. The general solution to the governing equations (Eqn. [1] and Eqn. [3]) is found by using the separation of variables technique and comprises cylinder functions as well as Bessel functions of the first and second kind (e.g., Kreyszig, 2010).

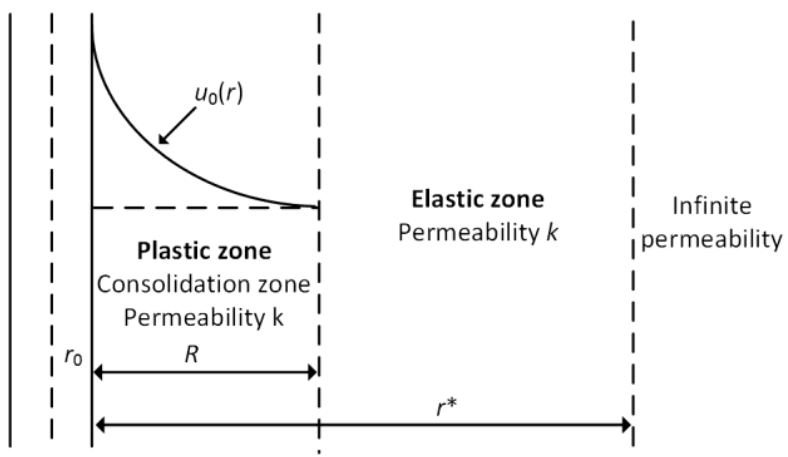

Fig. S1. Cylindrical cavity expansion parameters 
Randolph et al. (1979) used the expression for excess pwp proposed by Hill (1950) and Gibson et al. (1961) for an elastic-perfectly plastic soil as follows:

$$
\begin{array}{lll}
\text { [4] } & u_{0}=2 s_{\mathrm{u}} \ln \left(\frac{R}{r_{0}}\right) & r_{0} \leq r \leq R \\
\text { [5] } & u_{0}=0 & R<r<r^{*}
\end{array}
$$

Where $R=r_{0}\left(G / s_{\mathrm{u}}\right)^{1 / 2}$. By substituting the initial excess pwp into the general solution, the final solution for $u$ and $\xi$ over the radial domain can be found. These solutions are found by non-dimensionalising the time axis as $\tau=c t / r_{0}^{2}$ and can be solved through a macro enabled spreadsheet application. Further details are presented in King (2017).

\section{Field case study}

Additional data describing the porewater pressure response and lateral deformation as measured by Inclinometer No. 1 is presented below.

\section{Piezometer data}

The earth pressure cell (EPC) and strain gauges also show a similar generalized response during the Stage $3 \mathrm{~b}$ works as the piezometer (compare Fig. S2 and Fig. 7). The overburden pressure (2.7m height of embankment) remains constant during this five day period (see Fig. S3 for a cross section and Fig. 6 for the column layout in this area and King et al. 2017a). It is inferred that the large increase in vertical stress acting on the earth pressure cells is due to uplift pressures generated in the Coode Island Silt. This effect is most pronounced on the column (see EPC4 data) where it is inferred that the uplifted column is resisted by an active arching mechanism that develops in the overlying soil mass as indicated in the Area No. 1 cross section (Fig. S3.). Similarly, uplift pressure acting in the area between columns is inferred to cause the geogrid to deflect upward, resulting in tensile strain development (Fig. S2b). By comparison, the transverse geogrid layer showed no major strain development over the same period (King et al. 2017a). The different response observed by transverse and longitudinal layers of geogrid is due to the location of the anchorage zones. For the transverse layer anchorage zone located between row $\mathrm{G}$ and $\mathrm{H}$ columns it is inferred that the entire anchorage zone is uplifted, and as a result, minimal strain develops in the transverse layer. By comparison, the longitudinal layer is anchored at a distance sufficiently away from the installed drilled displacement columns, allowing the geogrid layer to resist uplift pressures. The result is the sharp increase in strain (Fig. S2b) correlating with the installation time of DDCs.

As this uplift pressure in the Coode Island Silt dissipates following column installation (Fig. 5 of journal paper), these tensile strains are also observed to reduce. The relatively uniform and temporary response of all longitudinal strain gauges during this period is consistent with the uplift/heave mechanism described; the observed behaviour cannot be explained by tensile strain induced by downward sagging of the geogrid (i.e., membrane action due to arching stresses).
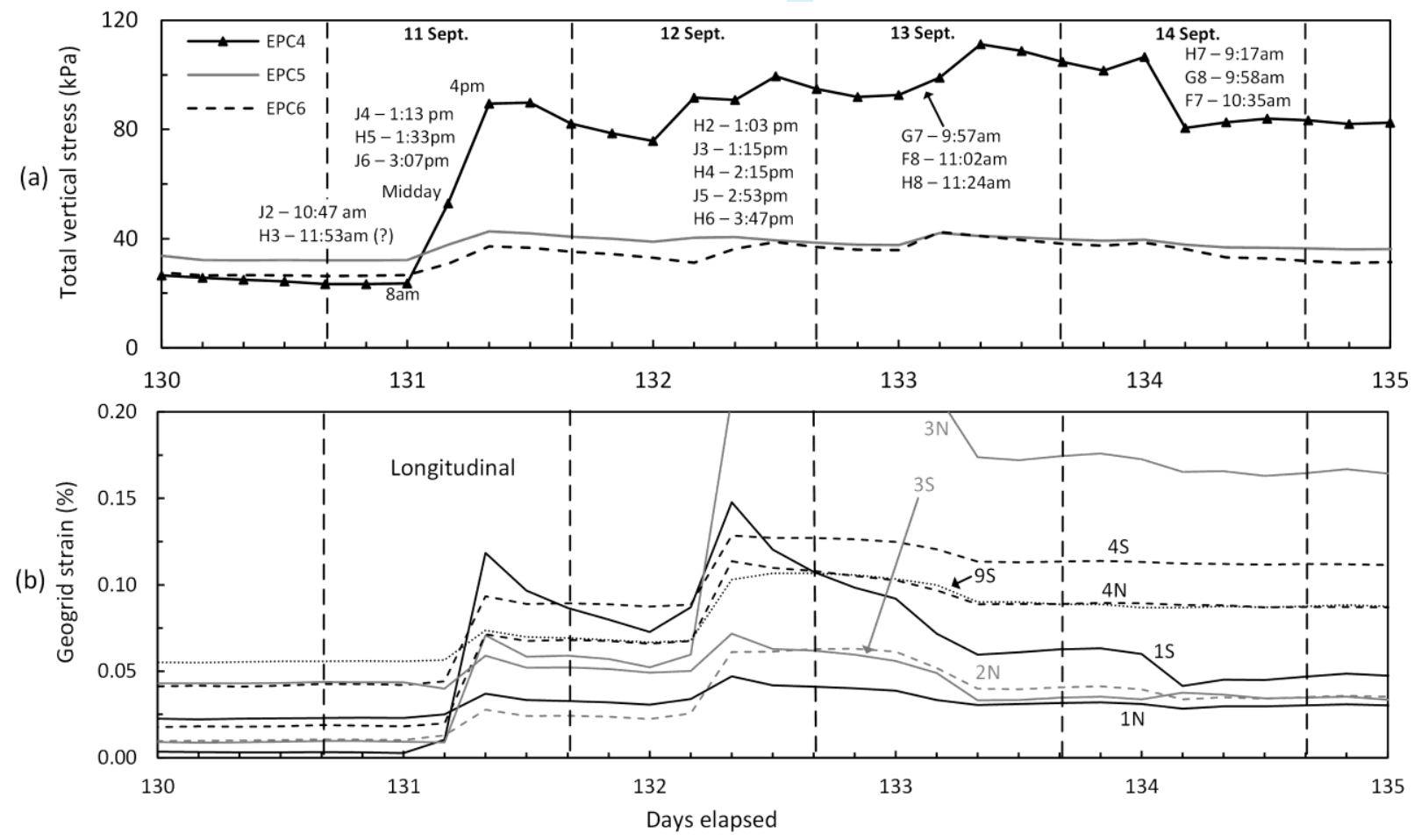

Fig. S2. Response of; (a) EPCs and (b) longitudinal strain gauges to column installation 


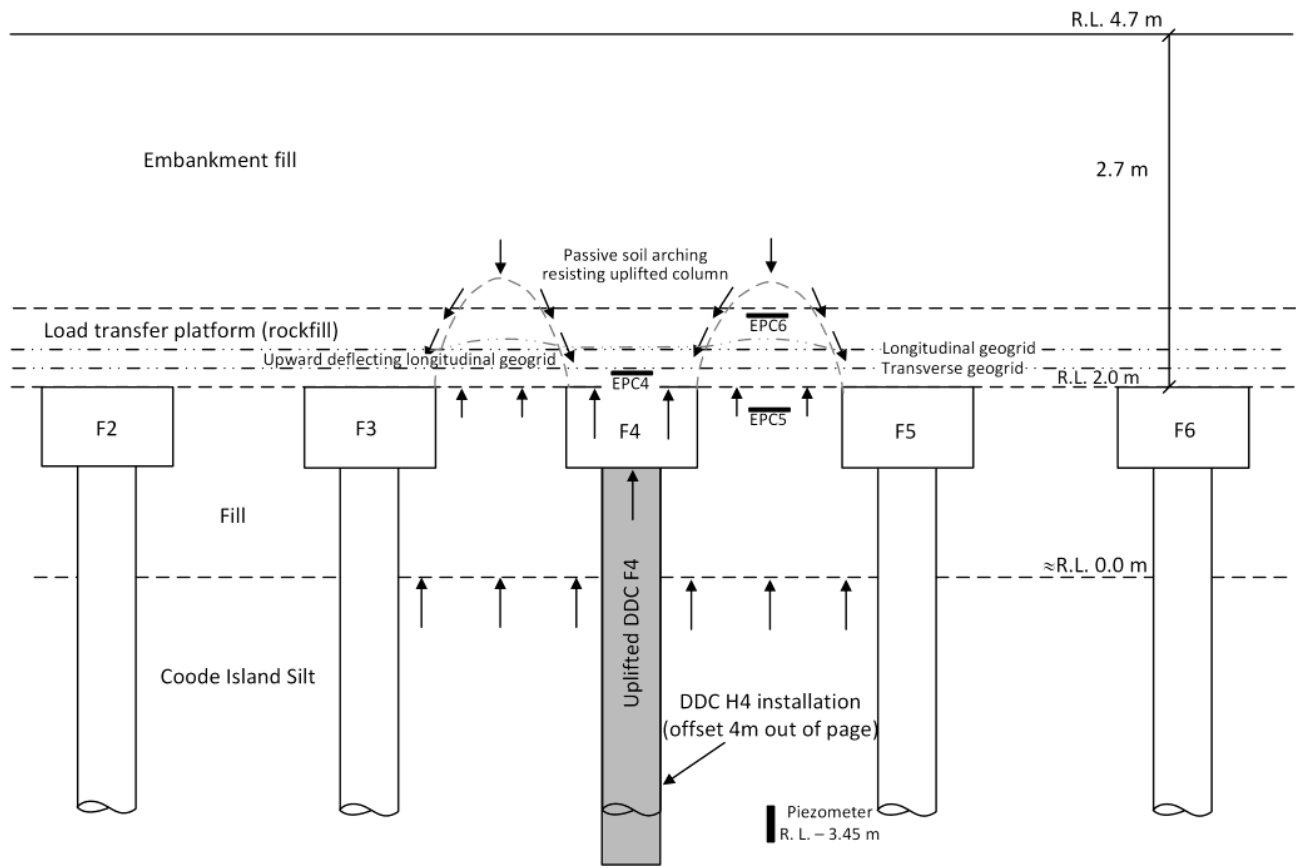

Fig. S3. Inferred applied loadings acting on area No. 1 instrumentation during Stage $3 b$ works

\section{Inclinometer No. 1 data}

The location of Inclinometer No. 1 and its axes along with date, time and location of adjacent drilled displacement columns is presented in Fig. S4. The column installations and inclinometer readings took place between 12 March to 3 April 2013 and are listed in Table S1. The inclinometer was decommissioned after the last reading taken on 3 April 2013. The lateral movement associated with the various phases (Fig. S5) is similar to the response measured by Inclinometer No. 2, although the general magnitude of movement is greater. This is consistent with the reduced radial distance of Inclinometer No. 1 relative to the installed columns. The lateral displacement profiles at the toe of the columns shows negligible movement $(<2 \mathrm{~mm})$ and matches closely with the shape of the auger head. It is likely that the stress condition at the shaft interface, near the base, more closely resembling that of a non-displacement piles i.e., an atrest $K_{\mathrm{o}}$ stress condition. The majority of the increase in shaft capacity is therefore likely to occur further up the shaft (at least $1.5 \mathrm{~m}$ above the toe) where the displacement body has fully displaced soil laterally.

Fig. S6 presents a vector diagram of soil movement at Relative Level (R.L.) (relative to mean sea level in Australia) of $-3.55 \mathrm{~m}$ assessed by Inclinometer No. 1 . The difference in the alignment between predicted and measured phase vectors can be attributed to time-dependent effects, with different columns in different phases of equilibration, which are not described by the linear superimposition of vectors. However, the general agreement is reasonable as the magnitude of soil displacement is dominated by the installation phase. The effect of the additional columns installed beyond the extent shown in Fig. S4 is also a contributory factor.

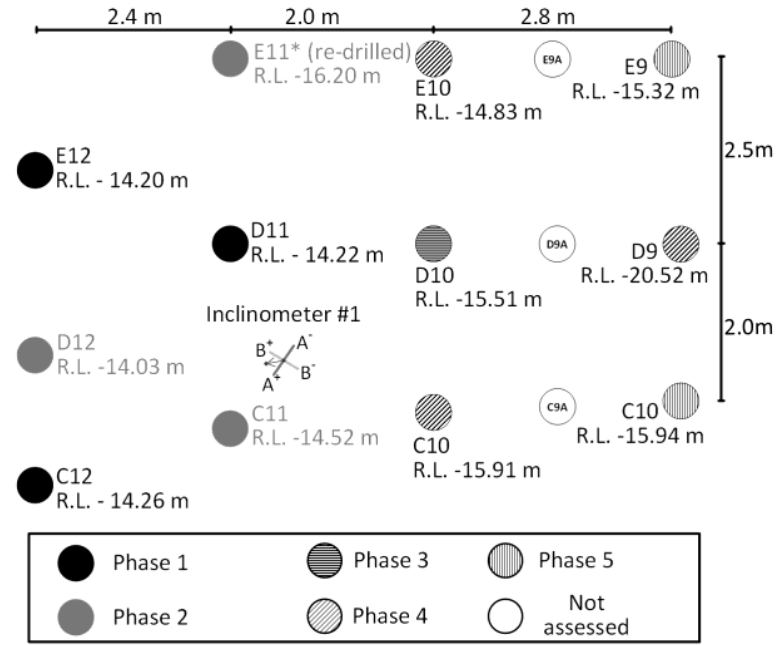

Fig. S4. Inclinometer No. 1 and DDC locations 
Table S1: Inclinometer No. 1 timeline

\begin{tabular}{|c|c|c|c|c|c|}
\hline Activity & Date \& Time & $\begin{array}{l}\text { Time from DDC install to } \\
\text { reading (hours:minutes) }\end{array}$ & Phase & $\begin{array}{c}\text { Radial distance } r \\
(\mathbf{m})\end{array}$ & $r / D$ \\
\hline $\mathrm{C} 12$ & 15 March 2:17 pm & $3: 39$ & \multirow{4}{*}{ Phase 1} & 3.47 & 7.7 \\
\hline E12 & 15 March 2:45 pm & $3: 11$ & & 3.99 & 8.9 \\
\hline D11 & 15 March 3:22 pm & $2: 34$ & & 1.71 & 3.8 \\
\hline Inclinometer reading & 15 March 5:22 pm & & & & \\
\hline E11 & 16 March 3:22 pm & 2 days, $4: 00$ & \multirow{4}{*}{ Phase 2} & 4.15 & 9.2 \\
\hline D12 & 18 March 1:49 pm & $3: 41$ & & 3.06 & 6.8 \\
\hline $\mathrm{C} 11$ & 18 March 2:41 pm & $2: 49$ & & 1.12 & 2.5 \\
\hline Inclinometer reading & 18 March 5:30 pm & & & & \\
\hline Inclinometer reading & 20 March 3:47 pm & & Phase 2b & & \\
\hline D10 & 25 March 2:26 pm & $17: 47$ & \multirow{2}{*}{ Phase 3} & 2.41 & 5.4 \\
\hline Inclinometer reading & 26 March 8:13 am & & & & \\
\hline E10 & 26 March 10:43 am & $21: 32$ & \multirow{4}{*}{ Phase 4} & 4.48 & 10.0 \\
\hline $\mathrm{C} 10$ & 26 March 11:21 am & $20: 54$ & & 1.96 & 4.4 \\
\hline D9 & 26 March 12:03 pm & $20: 12$ & & 5.13 & 11.4 \\
\hline Inclinometer reading & 27 March 8:15 am & & & & \\
\hline C9 & 27 March 10:49 am & 4 days $2: 11$ & \multirow{3}{*}{ Phase 5} & 4.92 & 10.9 \\
\hline E9 & 27 March 10:21 am & 4 days $2: 39$ & & 6.28 & 14.0 \\
\hline Inclinometer reading & 3 April 1:00 pm & & & & \\
\hline
\end{tabular}

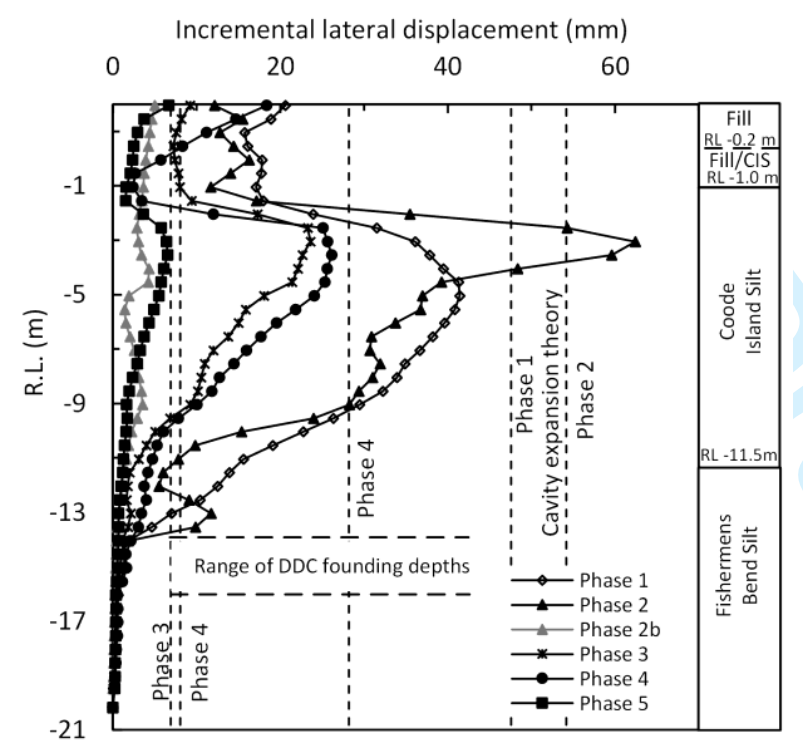

Fig. S5. Stratigraphy and Inclinometer No. 1 readings - incremental lateral displacement

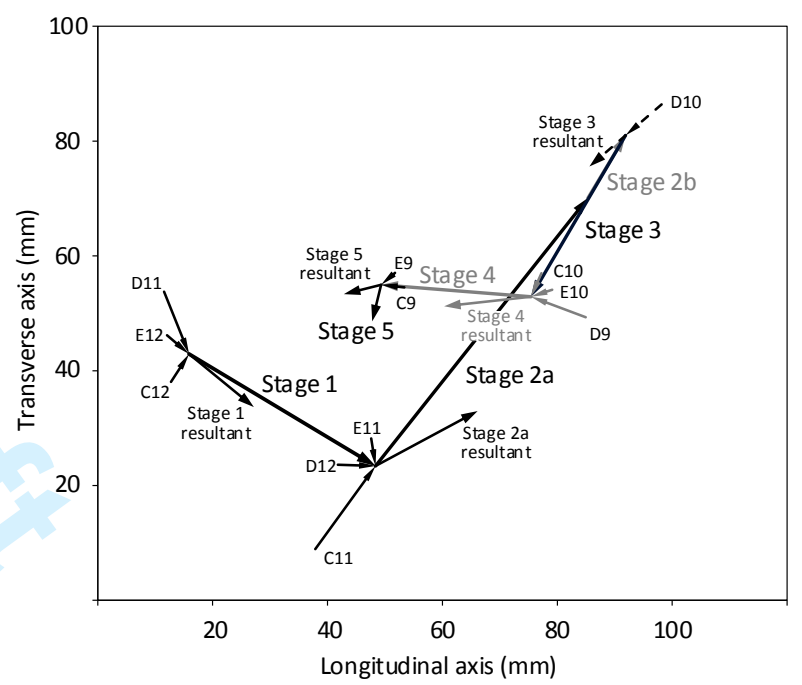

Fig. S6. Inclinometer No. 1 - vector diagram R.L. -3.55 m

\section{Effects on arching}

The collapse of the arching due to the Stage $3 \mathrm{~b}$ works was observed by the EPCs and tiltmeters (Fig. S7) in area No. 2 and was discussed briefly in King et al. (2017a) where the area No. 2 instrumentation was presented and discussed. Based on the inclinometer data (Fig. 10 and Fig. 11 in the journal paper), the tiltmeter data (Fig. S7) and the strong correlation with the installation times, it is likely that the primary cause of the arching collapse is lateral movement of the soil mass where arching is occurring (i.e. in the rockfill material). Vibrations caused by the piling works (rig tracking, drilling etc.) may be expected to contribute, however one would expect to observe this throughout the Stage $3 \mathrm{~b}$ works, which it is not the case. The nearest column installed as part of Stage 3b was G12 at a distance of $8.2 \mathrm{~m}(12.4$ D). Columns installation on day 133 were at $>10.2 \mathrm{~m}(20 \mathrm{D})$ and caused partial collapse of the arching. Additional column installations on Day 136 and 137 cause the arching to completely collapse and overburden conditions (57 $\mathrm{kPa})$ to be briefly established. From Equation [1] (from the journal paper) the lateral displacement is predicted to be $5.0 \mathrm{~mm}$ at $5 \mathrm{~m}$ and $2.5 \mathrm{~mm}$ at $10 \mathrm{~m}$ offset. These predictions, and the observed behaviour, highlight the susceptibility of the arching stresses to external disturbance. The behaviour observed here suggests that just several millimetres of lateral movement is sufficient to cause the arching to partially collapse. However, as described in King et al. (2017a), the arching stress quickly redevelop as the sub-soil settlement occurs under stresses close to the overburden pressure (i.e. 57 $\mathrm{kPa}$ in Fig. S7).

This behaviour highlights an important aspect of the arching stress-deformation relationship that is seldom recognized in GRCSEs. If arching collapses, in order for the arching stresses to reform this must be accompanied with sub-soil settlement and/or deflection of the geogrid layer for arching stresses to re-develop. Theoretically, this could lead to the geogrid layer being overstressed if repeatedly subjected to stresses close to the overburden pressure 


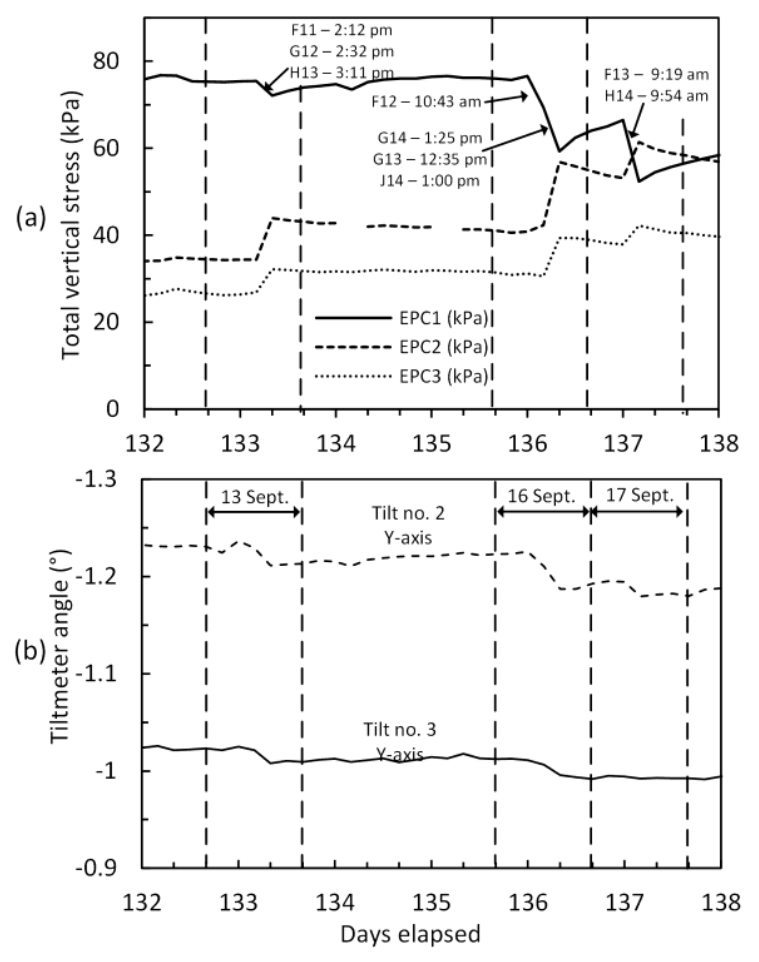

Fig. S7. (a) EPC and (b) tiltmeter response during Stage 3b works

(assuming the geosynthetic reinforcement was designed to resist much lower stresses such as those encountered near maximum arching). Earthquake loading, traffic loading and other forms of dynamic loading may provide the necessary repetitive conditions for this failure mechanism to develop over the long-term. This is described further in King et al. (2017b).

\section{Global scale mechanisms for embankments supported on drilled displacement columns}

\section{Structural response of drilled displacement columns}

As instruments to measure bending moments directly are not currently available it is common to calculate the bending moment indirectly from curvature and material properties as follows:

[6] $\quad M=\psi E I$

Where $M, \psi, E$ and $I$ are the bending moment, curvature, modulus of elasticity and second moment of inertia of the column respectively. A zero tensile strain condition occurs where the tensile stress induced in the column due to flexure is less than, or equal to, the axial (compressive) stress as shown in Fig. S8. To provide an indication of the range of allowable lateral displacement under the zero tensile strain condition, profiles of (idealized) lateral displacement are shown in Fig. $\mathrm{S} 9$ for cases where applied stresses of $75 \mathrm{kPa}\left(\sigma_{\mathrm{N}}=472 \mathrm{kPa}\right)$ and $150 \mathrm{kPa}\left(\sigma_{\mathrm{N}}=943 \mathrm{kPa}\right)$ are acting on the $1 \mathrm{~m}$ by $1 \mathrm{~m}$ square DDC head and where $\sigma_{\mathrm{N}}$ is the stress acting in the $450 \mathrm{~mm}$ diameter column shaft. These two cases approximate the stress acting on the DDC head under conditions on no arching (i.e., overburden pressure) and maximum arching respectively. The idealized lateral displacement profiles assume a fixed base, pinned rotational condition at the head and uniform curvature along the shaft. As a result, the bending moment is uniform along the length of the column. For the case of maximum arching, the maximum lateral displacement satisfying a zero-tensile strain condition is $18 \mathrm{~mm}$ at the DDC head. If tensile strain is permitted, the DDCs can be displaced $85 \mathrm{~mm}$ laterally at the DDC head under maximum arching before cracking occurs. Under this condition the bending moment is equal to the cracking moment $\left(M_{\mathrm{cr}}\right)$ calculated from Eqn. [7]. Where $f_{\mathrm{r}}$ is the flexural tensile strength of concrete (modulus of rupture), $I_{\mathrm{g}}$ the gross second moment of inertia and $y_{\mathrm{t}}$ the distance from the centroid to the extreme fibre.

[7] $\quad M_{\mathrm{cr}}=\frac{f_{\mathrm{r}} I_{\mathrm{g}}}{y_{\mathrm{t}}}$

In addition, a zero applied load condition is considered. This is similar to the conditions that exist during ground improvement works where a DDC is displaced by an adjacent column (contribution of column self weight is minimal and ignored). In Fig. 16 (of the journal paper) the long term transverse movement (day 161 to 741 ) of the inclinometer was considered (see also Fig. 12 of journal paper). It is assumed that the lateral displacement profile of the column C15 is approximated by Inclinometer No. 2; the general agreement between the embedded tiltmeters and Inclinometer No. 2 has been described previously and the correlation was good. Furthermore, lateral soil arching can be expected to lead to 


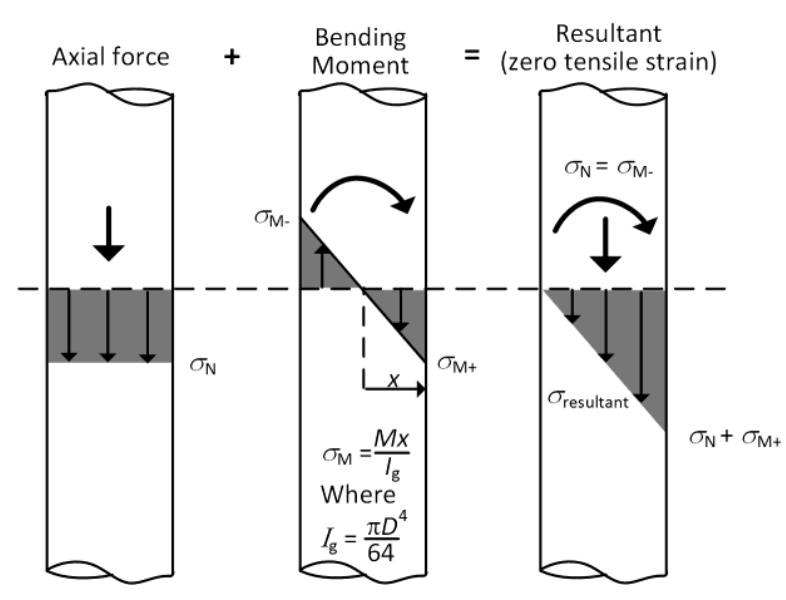

Fig. S8. Calculation of applied loading on DDCs

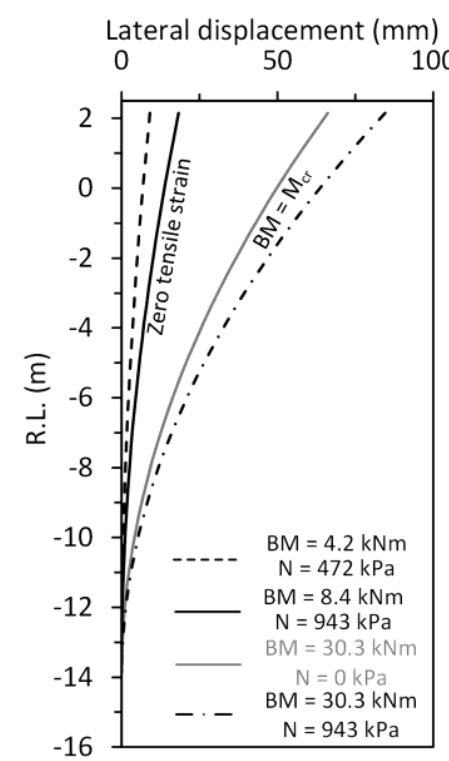

Fig. S9. Idealized lateral displacement profiles for zero tensile strain condition and bending moment equal to $M_{\mathrm{cr}}$ condition

increased lateral load attraction, due to columns being stiffer than the surround soft soil. This makes the columns more likely to move with the soft soil. In Fig. S9 idealized lateral displacement profiles were shown, the behaviour is similar to that which might be expected if lateral sliding is considered in isolation. However, the long term behaviour is more complex due to the combined effect of lateral sliding and equilibration (radial consolidation). As a result, the lateral displacement profile (Fig. S10a) and the internal bending moments in the DDC are also more complex.

For inclinometer derived lateral displacement profiles, curvature can be calculated using Eqn. [8], however, typically $\mathrm{d} z / \mathrm{d} w$ is assumed to be close to zero and the approximate expression (Eqn. [9]) is adopted. Using this approach the curvature can be calculated directly from a lateral displacement profile, however, this typically leads to erratic results (Fig. S10b). To more accurately calculate the bending moment profile curve fitting techniques applied to the displacement profile are required.

[8] $\psi=\frac{\frac{\mathrm{d}^{2} w}{\mathrm{~d} z^{2}}}{\left[1+\left(\frac{\mathrm{d} w}{\mathrm{~d} z}\right)^{2}\right]^{3 / 2}}$

[9] $\quad \psi \sim \frac{\mathrm{d}^{2} w}{\mathrm{~d} z^{2}}$

In Fig. S10a the lateral displacement is globally fitted with a higher $\left(6^{\text {th }}\right)$ order polynomial and an excellent fit is obtained $\left(R^{2}=0.986\right)$. In Fig. S10b the bending moment profile is shown based on the higher order polynomial as well as the bending moment profile calculated directly from the inclinometer data with the latter case showing a highly erratic result. The various sources of error in the inclinometer measurement which leads these erratic results are summarized by Ooi et al. (2003); it is the variability in the back-calculated bending moment profile which necessitates the use of curve fitting methods. Ooi et al. (2003) presented a comprehensive comparison of 12 curve fitting methods applied to 60 sets of inclinometer data and concluded that a piecewise cubic curve fitting over a 5 point window generally resulted in the best estimate of back-calculated bending moment profiles. The piecewise cubic curve fitting approach fits a cubic polynomial $w=A z^{3}+B z^{2}+C z+D$ over a moving window of data points, in Fig. S10 the 5-point data window recommended by Ooi et al. (2003) is shown along with larger data windows (9 no., 11 no., and 13 no.). These piecewise cubic functions are fitted over a moving window of adjacent data points. At an individual data point the curvature can be calculated explicitly from Eqn. [10] and averaged from the various fitted cubic functions.

$$
\psi \sim \frac{\mathrm{d}^{2} w}{\mathrm{~d} z^{2}}=6 A z+2 B
$$

The use of increasingly larger data windows results in increased "smoothing" of the data sets. Engineering judgement is required to obtain a balance between a "smoothed" profile and localized behaviour. By comparison, the five-point data window shows variable results that are only slightly improved from the raw data. The five-point data window is judged not to be reasonable for this particular case, however, the larger data windows show increasing smoothing of the bending moment profile and with near identical maximum bending moments; the 11-point data window is adopted as 
(a)

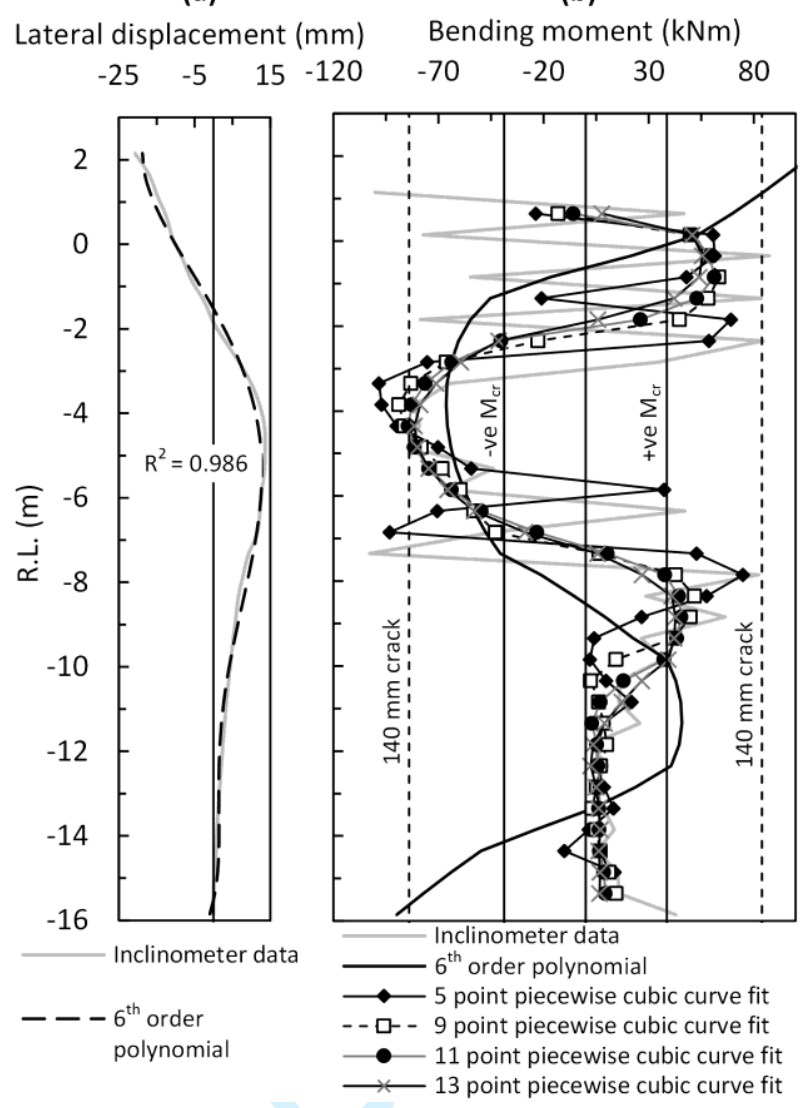

Fig. S10. (a) Post-construction displacement of Inclinometer No. 2 and (b) inferred bending moment acting on DDC C15

the preferred method in the subsequent analysis. The higher order polynomial shows unusual behaviour in the bending moment profile at the top and bottom of the DDC, this is observed as a "kick" at the top and bottom of the fitted displacement profile and is a common source of error when using higher order polynomials (Ooi et al. 2003). Furthermore, the higher order polynomial does not appear to capture the localisation of larger bending moments well. Similar behaviour was observed with $4^{\text {th }}$ and $5^{\text {th }}$ order polynomials and as recommended by Ooi et al. (2003) these are not used here.

Where the bending moment exceeds $M_{\mathrm{cr}}$, cracking of the column will occur and as result the cross sectional area is reduced. The effective moment of inertia $I_{\mathrm{e}}$ for a cracked section is calculated as follows (Branson 1977):

$$
I_{\mathrm{e}}=\left[\frac{M_{\mathrm{cr}}}{M}\right]^{3} I_{\mathrm{g}}+\left[1-\left(\frac{M_{\mathrm{cr}}}{M}\right)^{3}\right] I_{\mathrm{cr}} \leq I_{\mathrm{g}}
$$

Where $I_{\mathrm{cr}}$ is the second moment of inertia of a transformed cracked section. The bending moment profiles shown in Fig. $\mathrm{S} 10 \mathrm{~b}$ is calculated based on the axial stress at on the DDC head of $150 \mathrm{kPa}$ and approximates the stress acting on DDC C15 post-construction. The values of positive and negative $M_{\mathrm{cr}}$ are indicated in Fig. S10b with a bending moment of 88 $\mathrm{kNm}$ occurring at R.L. $-4 \mathrm{~m}$. The depth of cracking is assessed to be $140 \mathrm{~mm}$ at this depth. It is important to note that flexural failure of unreinforced concrete is a brittle failure mechanism and that the use of Eqn. [7] and Eqn. [11] is not strictly valid; the calculated crack depth should be considered as first order approximation only. The brittle failure mechanism of unreinforced concrete means that crack depths may be greater. The bending moment profile also exceeds $M_{\mathrm{cr}}$ in the lower and upper portion of the shaft.

The observed embankment highlights that despite the long-term lateral sliding being approximately within the allowable limits which satisfy the zero tensile strain (Fig. S9) i.e., about $20 \mathrm{~mm}$, bending moments induced in the DDC are significantly larger than those predicted based on a lateral sliding mechanism alone. Furthermore, the embankment post-construction survey which is commonly employed in design scenarios validates only the lateral sliding behaviour and does little to reveal the additional loadings due to radial equilibration occurring below the ground surface. The additional lateral displacement induced in the DDCs due to the radial equilibration, which has acted long term in the opposite direction, has significantly increased the bending moments and as a result increased the amount of cracking of the DDC shaft than would have otherwise been expected based on lateral sliding alone.

\section{Drilled displacement column installation layout}

A typical hit-1 miss-1 layout plan is shown in Fig. S11 for the installation of ground improvement elements. 


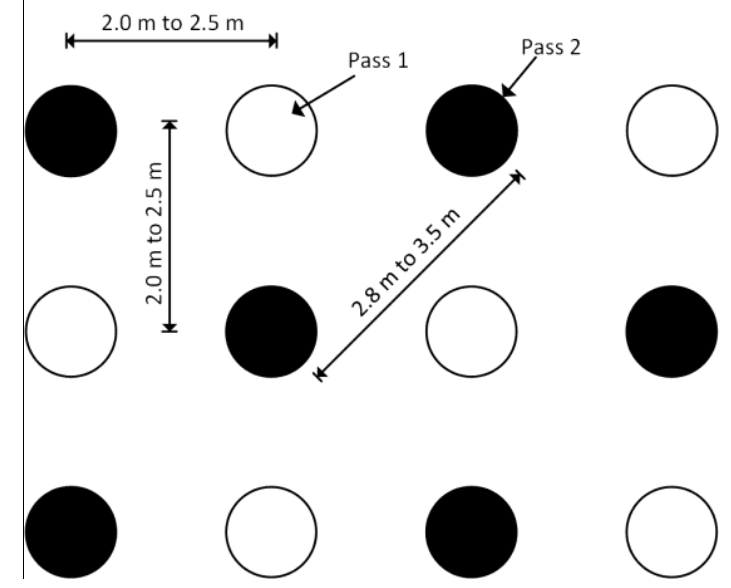

Fig. S11. DDC installation layout plan

\section{References}

Branson, D. E. (1977). Deformation of concrete structures. McGraw-Hill Companies, New York. pp. 576.

Gibson, R. and Anderson, W. (1961). In situ measurement of soil properties with the pressuremeter. Civil Engineering and Public Works Review, 56(658): 615-618.

Hill, R. (1950). The mathematical theory of plasticity. Clarendon Press, Oxford, UK. pp.

King, D. J. 2017. The behaviour and performance of geosynthetic reinforced column supported embankments . Ph.D. thesis, Department of Civil Engineering, Monash University, Melbourne, Australia

King, D. J., Bouazza, A., Gniel, J., Rowe, K. R. and Bui, H. H. (2017a). Load transfer platform behaviour in embankments supported on semi-rigid columns: implications of the ground reaction curve. Canadian Geotechnical Journal, 54(8):1158-1175. doi: 10.1139/cgj-2016-0406

King, D. J., Bouazza, A., Gniel, J., Rowe, K. R. and Bui, H. H. (2017b). Serviceability behaviour in geosynthetic reinforced column supported embankments. Geotextiles and Geomembranes, 45(4): 261-279. doi: 10.1016/j.geotexmem.2017.02.006

Kreyszig, E. (2010). Advanced engineering mathematics, $9^{\text {th }}$ edition. John Wiley \& Sons. pp. 1094.

Ooi, P. and Ramsey, T. (2003). Curvature and bending moments from inclinometer data. International Journal of Geomechanics, 3(1): 64-74.

Randolph, M. F. and Wroth, C. (1979). An analytical solution for the consolidation around a driven pile. International Journal for Numerical and Analytical Methods in Geomechanics, 3(3): 217-229. 